\title{
An Engineered Metal Sensor Tunes the Kinetics of Synaptic Transmission
}

\author{
(1)Chantell S. Evans, ${ }^{1,2,3 *}$ David A. Ruhl, ${ }^{1,2,4 *}$ and Edwin R. Chapman ${ }^{1,2,3,4}$ \\ ${ }^{1}$ Department of Neuroscience, ${ }^{2}$ Howard Hughes Medical Institute, ${ }^{3}$ Molecular and Cellular Pharmacology Program, and ${ }^{4}$ Neuroscience Training Program, \\ University of Wisconsin, Madison, Wisconsin 53705-2275
}

The $\mathrm{Ca}^{2+}$ sensor synaptotagmin-1 (syt-1) regulates neurotransmitter release by interacting with anionic phospholipids. Here we test the idea that the intrinsic kinetics of syt-membrane interactions determine, in part, the time course of synaptic transmission. To tune the kinetics of this interaction, we grafted structural elements from the slowest isoform, syt-7, onto the fastest isoform, syt-1, resulting in a chimera with intermediate kinetic properties. Moreover, the chimera coupled a physiologically irrelevant metal, $\mathrm{Sr}^{2+}$, to membrane fusion in vitro. When substituted for syt-1 in mouse hippocampal neurons, the chimera slowed the kinetics of synaptic transmission. Neurons expressing the chimera also evinced rapid and efficient $\mathrm{Sr}^{2+}$ triggered release, in contrast to the weak response of neurons expressing syt-1. These findings reveal presynaptic sensor-membrane interactions as a major factor regulating the speed of the release machinery. Finally, the chimera failed to clamp the elevated spontaneous fusion rate exhibited by syt-1 KO neurons, indicating that the metal binding loops of syt-1 regulate the two modes of release by distinct mechanisms.

Key words: EPSC kinetics; exocytosis; membrane penetration; synaptic transmission; synaptotagmin

\section{Significance Statement}

In calcium, synaptotagmin-1 triggers neurotransmitter release by interacting with membranes. Here, we demonstrate that intrinsic properties of this interaction control the time course of synaptic transmission. We engineered a "chimera" using synaptotagmin-1 and elements of a slower isoform, synaptotagmin-7. When expressed in neurons, the chimera slowed the rate of neurotransmitter release. Furthermore, unlike native synaptotagmin-1, the chimera was able to function robustly in the presence of strontium-a metal not present in cells. We exploited this ability to show that a key function of synaptotagmin-1 is to penetrate cell membranes. This work sheds light on fundamental mechanisms of neurotransmitter release.

\section{Introduction}

The fusion of synaptic vesicles (SVs) with the presynaptic plasma membrane is catalyzed by SNARE proteins: vesicular ( $\left.\mathrm{v}^{-}\right)$and target membrane ( $\mathrm{t}-$ ) SNAREs assemble into four-helix bundles that form the core of a conserved membrane fusion machine. A SV protein, p65/synaptotagmin-1 (syt-1; Matthew et al., 1981; Perin et al., 1990), binds $\mathrm{Ca}^{2+}$ via tandem C2 domains (Brose et

\footnotetext{
Received April 30, 2015; revised June 23, 2015; accepted June 24, 2015.

Author contributions: C.S.E., D.A.R., and E.R.C. designed research; C.S.E. and D.A.R. performed research; C.S.E. and D.A.R. analyzed data; C.S.E., D.A.R., and E.R.C. wrote the paper.

This work was supported by NIH Grant MH061876. C.S.E was supported by a PhRMA Foundation predoctoral fellowship and University of Wisconsin-Madison Molecular and Cellular Pharmacology Training Grant 5T32GM008688. D.A.R. was supported by a National Science Foundation Graduate Research Fellowship Program Grant DGE-1256259 and Neuroscience Training Program Grant T32-GM007507. E.R.C. is an investigator at the Howard Hughes Medical Institute.

${ }^{*}$ C.S.E. and D.A.R. contributed equally to this work.

The authors declare no competing financial interests.

Correspondence should be addressed to Edwin R. Chapman, Howard Hughes Medical Institute, University of Wisconsin, 1111 Highland Avenue, Madison, WI 53705-2275. E-mail: chapman@wisc.edu.

DOI:10.1523/JNEUROSCI.1694-15.2015

Copyright $\odot 2015$ the authors $\quad 0270-6474 / 15 / 3511769-11 \$ 15.00 / 0$
}

al., 1992) and has been identified as a $\mathrm{Ca}^{2+}$ sensor that triggers rapid SV exocytosis, as deletion of syt-1 results in a loss of synchronous synaptic transmission (DiAntonio and Schwarz, 1994; Geppert et al., 1994; Littleton et al., 1994; Mackler et al., 2002; Nishiki and Augustine, 2004), and $\mathrm{Ca}^{2+} \cdot$ syt-1 accelerates SNARE-catalyzed fusion in vitro (Fig. 1; Tucker et al., 2004). There are 17 known isoforms of syt (Dean et al., 2012), and the isoforms that trigger fusion (Bhalla et al., 2008) exhibit a wide range of $\mathrm{Ca}^{2+}$ binding affinities (Bhalla et al., 2005) and membrane binding kinetics (Hui et al., 2005). Whether these differences in intrinsic kinetics have functional consequences is not known.

The nonphysiological divalent cation $\mathrm{Sr}^{2+}$ has been used to probe the kinetics of neurotransmitter release, because replacement of extracellular $\mathrm{Ca}^{2+}$ with equimolar $\mathrm{Sr}^{2+}$ yields substantially reduced EPSCs with a largely asynchronous time course (Goda and Stevens, 1994; Rumpel and Behrends, 1999; XuFriedman and Regehr, 2000; Lau and Bi, 2005). $\mathrm{Sr}^{2+}$ readily enters presynaptic boutons through voltage-gated channels, but endogenous $\mathrm{Ca}^{2+}$ binding proteins are largely ineffective at buff- 
A
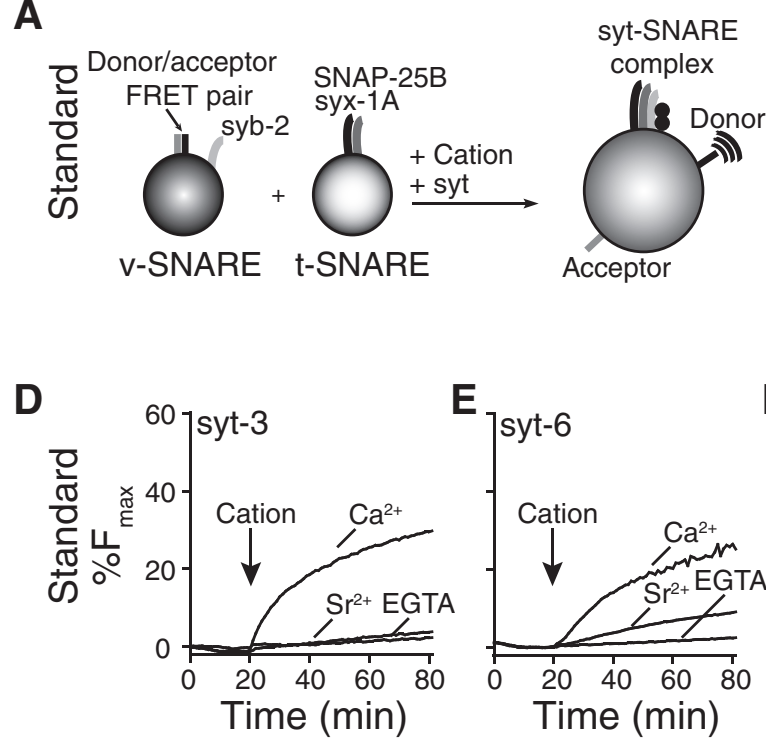

H

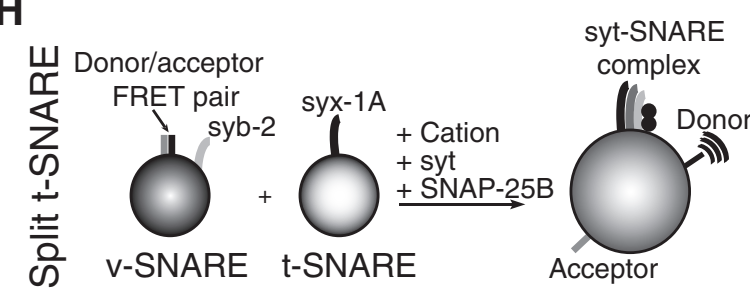

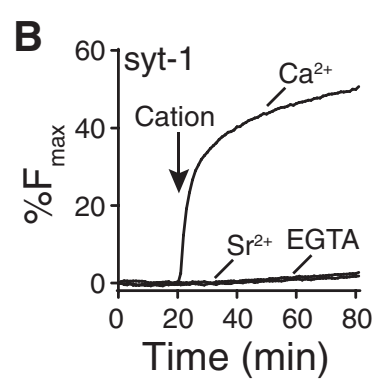

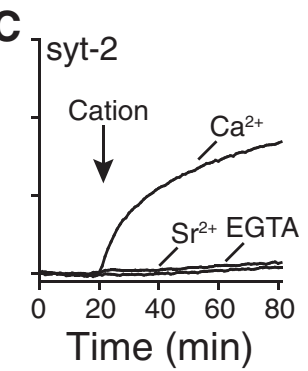

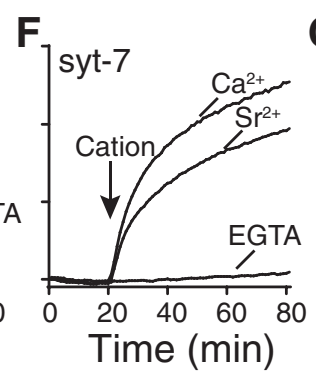

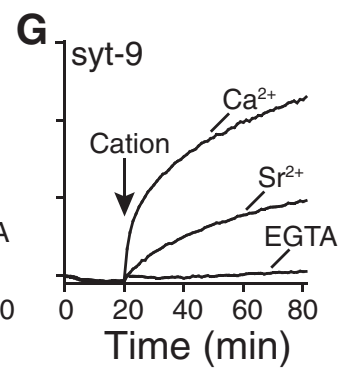

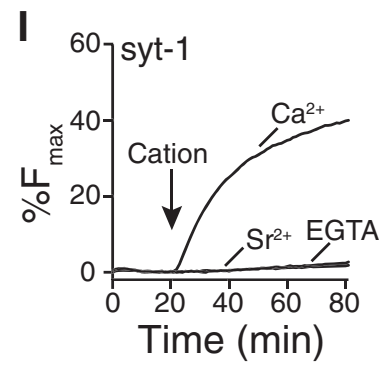

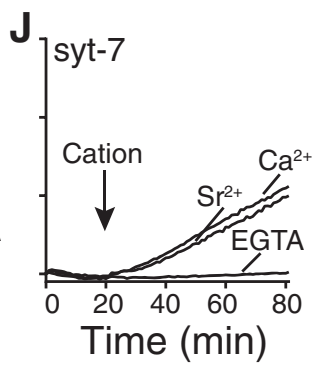

Figure 1. Identification of syt isoforms that are activated by $\mathrm{Sr}^{2+}$. $\boldsymbol{A}$, Schematic of standard in vitro fusion assay. $\boldsymbol{B}-\mathbf{G}$, Eight isoforms of syt sense $\mathrm{Ca}^{2+}$ (Hui et al., 2005), and six of these were

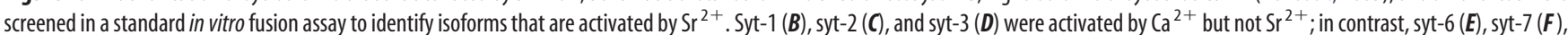

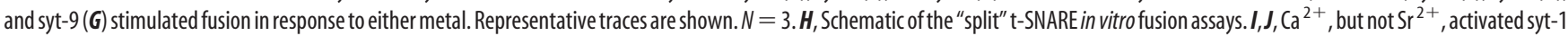
(I); Syt-7 efficiently facilitated fusion, in the presence of $\mathrm{Ca}^{2+}$ or $\mathrm{Sr}^{2+}(\boldsymbol{J})$. Representative traces are shown. $N \geq 4$.

ering $\mathrm{Sr}^{2+}$, leading to a $\mathrm{Sr}^{2+}$ transient that can persist for seconds (Rumpel and Behrends, 1999; Xu-Friedman and Regehr, 2000; Babai et al., 2014).

The goal of this study was twofold: first, to determine whether the intrinsic kinetics of syt determine the rate of neurotransmitter release, and second, to use a novel chemical genetic approach to engineer a sensor that responds to $\mathrm{Sr}^{2+}$. Therefore, a chimera between the fastest syt (syt-1) and a slower isoform, which responds to $\mathrm{Sr}^{2+}$, was generated. This chimera exhibited slower intrinsic membrane binding kinetics and slowed the rate of neurotransmitter release in neurons, arguing that EPSC decay kinetics are partially governed by the intrinsic kinetics of the presynaptic $\mathrm{Ca}^{2+}$ sensor. Furthermore, our modifications conferred upon syt-1 the ability to both penetrate membranes in vitro and trigger synchronous release in vivo in response to $\mathrm{Sr}^{2+}$, consistent with the notion that penetration of the target membrane by syt- 1 is a key step in SV exocytosis. Additionally, we dissociate evoked exocytosis from spontaneous single vesicle fusion, identifying a role for the metal binding loops of syt-1 in suppressing "miniature" release.

\section{Materials and Methods}

Materials. The following lipids were purchased from Avanti Polar Lipids: 1-palmitoyl-2-oleoyl-sn-glycero-3-phosphoethanolamine [phosphatidylethanolamine (PE)]; 1,2-dioleoyl-sn-glycero-3-phospho-l-serine [phosphatidylserine (PS)]; 1-palmitoyl-2-oleoyl-sn-glycero-3-phosphocholine [phosphatidylcholine (PC)]; 1,2-dipalmitoyl-sn-glycero-3phospho-ethanolamine- $N$-(7-nitro-2-1,3-benzoxadiazol-4-yl) (NBD-PE); $N$-(lissamine rhodamine B sulfonyl)-1,2-dipalmitoyl-sn-glycero-3- phosphoethanolamine (rhodamine-PE); and 1,2-dioleoyl-sn-glycero-3phosphoethanolamine- $N$-(5-dimethylamino-1-naphthalenesulfonyl) (dansyl-PE). $N, N^{\prime}$-dimethyl- $N$-(iodoacetyl)- $N^{\prime}$-(7-nitrobenz-2-oxa1,3-diazol-4-yl)ethylenediamine (IANBD-amide) was purchased from Invitrogen. Accudenz was purchased from Accurate Chemical \& Scientific Corporation. Glutathione Sepharose and $\mathrm{Ni}^{2+}$ Sepharose High Performance affinity media were obtained from GE Healthcare Bio-Sciences.

Recombinant proteins and protein purification. cDNA encoding the cytoplasmic domain (denoted C2AB) of rat syt-1 (residues 96-421; the amino acid residues for all other syt constructs below are indicated in parentheses) was provided by T. C. Südhof (Department of Molecular and Cellular Physiology, Howard Hughes Medical Institute, Stanford University, Stanford, $\mathrm{CA})$; the D374 mutation was corrected by replacement with a glycine. cDNA for syt-2 (C2AB, 139-423), syt-6 (C2AB, 143-426), syt-7 (C2AB, 134-403), and syt-9 (C2AB, 104-386) were provided by M. Fukuda (Department of Developmental Biology and Neurosciences, Tohoku University, Sendai, Miyagi, Japan). cDNA encoding syt-3 (C2AB, 290-569) was provided by S. Seino (Department of Physiology and Cell Biology, Kobe University Graduate School of Medicine, Kobe, Japan). W. A. Catterall (Department of Pharmacology, University of Washington, Seattle, WA) provided $\alpha 1 \mathrm{~B}$-synprint in a $\mathrm{p}$ TrcHis vector.

Syt-1 C2AB was subcloned into pGEX vectors to generate GST-tagged fusion proteins. Syt-2, syt-6, syt-7 and syt- $9 \mathrm{C} 2 \mathrm{AB}$ were subcloned into a pTrcHis vector, and syt- $3 \mathrm{C} 2 \mathrm{AB}$ was subcloned into a pET28a vector, to generate $\mathrm{His}_{6}$-tagged fusion proteins.

Chimeras and cysteine mutant forms of syt-1 and chimera ${ }_{1,3}$ were generated using PCR and a QuikChange Site-Directed Mutagenesis Kit (Stratagene). Chimeras were generated by grafting the metal binding 
A

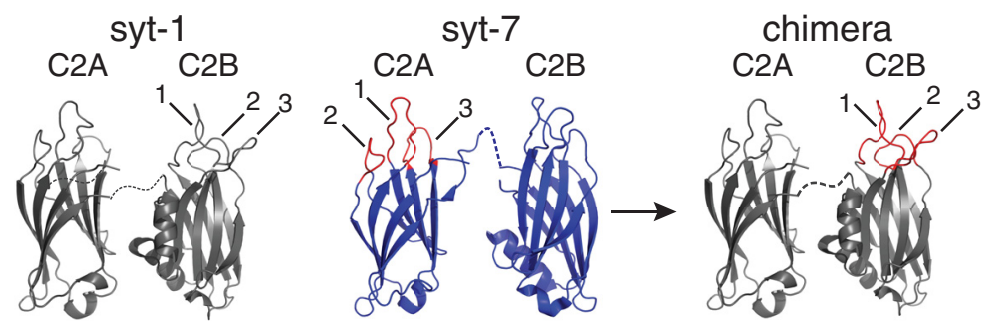

B

Loop 1

syt-1 C2B KLGDICFSLRYVPTAGKLTVVILEAKN LKKMDVGGLSDPYVKI HLMQNGKRLKKKKTTI 59

syt-7 C2A NLGRIQFSVGYNFQESTLTVKVMKAQELPAKDFSGTSDPFVKIYLLPDKK--HKLETKV 57

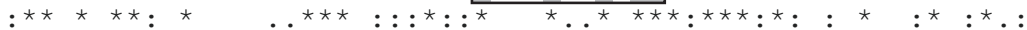

Loop 2 Loop 3

syt-1 C2B KKNTLNPYYNESFSFE-VPFEQIQKVQVVVTVLDYDKIGKNDAIDKVFVGYNSTGAELR 117

syt-7 C2A KRKNLNPHWNETELFEGFPYEKVVQRI LYLQVLDYDRFSRNDPIGEVS IPLN------- 107

${ }^{\star}::{ }^{\star \star \star}::{ }^{\star \star}:{ }^{\star \star}{ }^{\star}{ }^{\star}::::::^{\star \star \star \star \star *}:::^{\star \star} .{ }^{\star} .:^{\star}:{ }^{\star}$

syt-1 C2B HWSDILANPRRPIAQWHTLQVEEEVDAMLAVKK 150

syt-7 C2A -----KVDLTQMQTFWKDLKPCSDGS------- 130
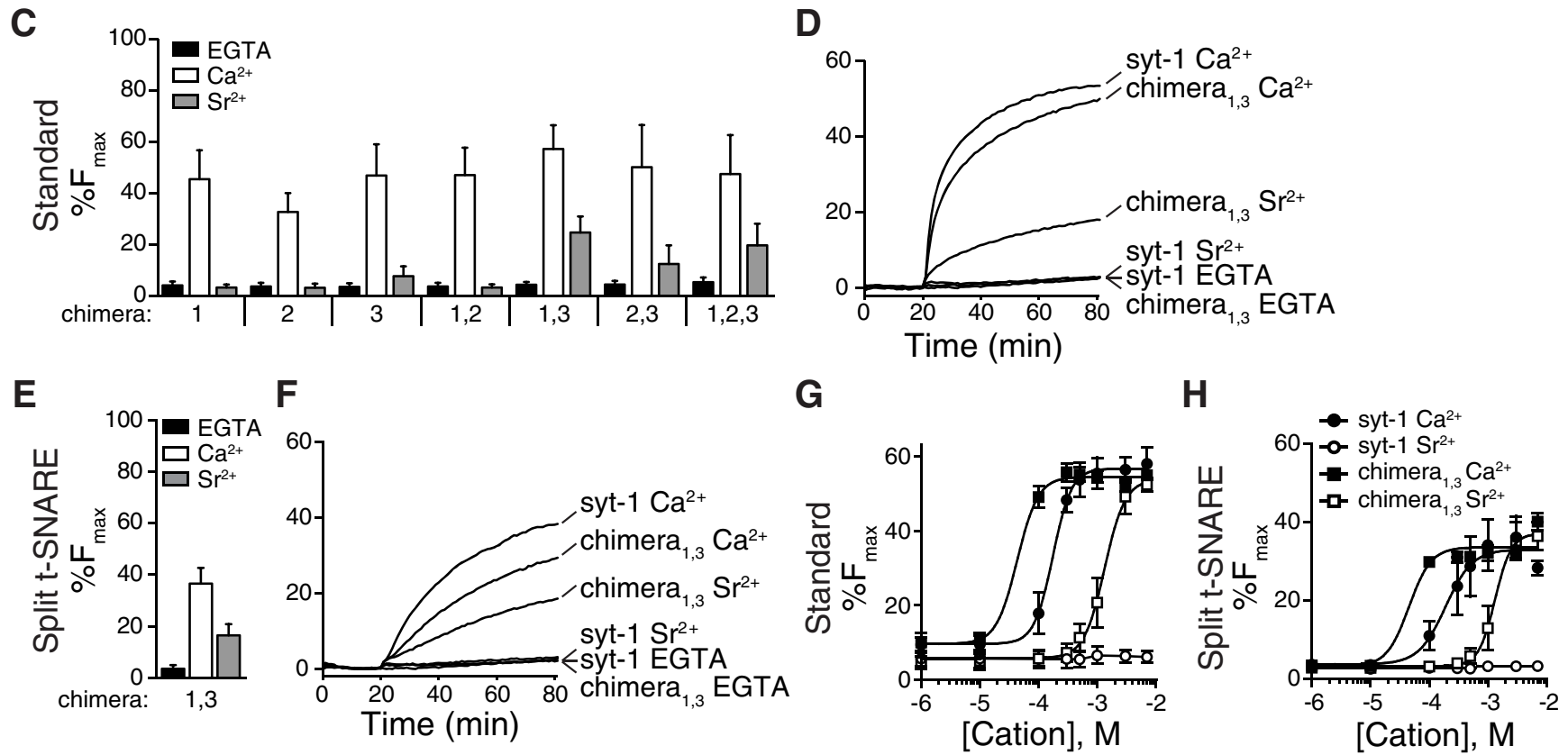

Figure 2. Engineering an $\mathrm{Sr}^{2+}$-activated syt-1/7 chimera. $A$, Structural models depicting the cytoplasmic domains of syt-1 (gray; $(2$ domains reoriented from Fuson et al., 2007 ) and syt-7 (blue; C2A from PDB file 2D8K, C2B from Xue et al., 2010). These structures were oriented and connected with a dashed line using a drawing program. The metal binding loops of syt- 1 (2B (gray) were replaced with the analogous loops from syt-7 C2A (red). B, Alignment of syt-1 C2B and syt-7 C2A. Metal binding loops are boxed, and identical residues are highlighted in gray. C, D, Chimeras were initially screened in the standard in vitro fusion assay. In $\mathrm{Ca}^{2+}$, all seven constructs stimulated fusion; in $\mathrm{Sr}^{2+}$, four constructs stimulated fusion, but chimera ${ }_{1,3}$ was the most active (C). For comparison, representative traces for syt- 1 and chimera ${ }_{1,3}$ are shown for both metals $(\boldsymbol{D})$. $\boldsymbol{E}_{\boldsymbol{F}} \boldsymbol{F}$, (himera 1,3 was further analyzed in the split t-SNARE version of the assay and facilitated fusion in the presence of $\mathrm{Ca}^{2+}$ or $\mathrm{Sr}^{2+}(\boldsymbol{E})$. Shown are representative traces for syt-1 and chimera $1,3(\boldsymbol{F})$. For panels $(\boldsymbol{C})$ and $(\boldsymbol{E})$, the extent of fusion after 80 min was plotted. $N \geq 3 . \boldsymbol{G}, \boldsymbol{H}, \mathrm{Scatter}$ plots of cation titrations in the standard $(\boldsymbol{G})$ and split t-SNARE $(\boldsymbol{H})$ fusion reactions were performed using the indicated free [cation] $\left(\mathrm{Ca}^{2+}{ }^{2} \mathrm{Sr}^{2+}\right) \cdot N \geq 3$. See Table 1 for [cation] $]_{1 / 2}$ and Hill coefficients for syt-1and chimera ${ }_{1,3}$-regulated fusion in $\mathrm{Ca}^{2+}$ and $\mathrm{Sr}^{2+}$. Error bars indicate SEM.

loops of syt-7 C2A (loop 1, 162-172; loop 2, 192-198; loop 3, 225-233) onto syt-1 C2B. For cysteine mutants, first the lone native cysteine, C277, was mutated to an alanine. Then, a single cysteine was introduced at M173 and F234 of C2A and V304 and I367 of C2B for syt-1 and M173 and F234 of C2A and F304 and F367 of C2B for chimera 1,3 .

cDNA for SNAP-25B was provided by M. C. Wilson (Department of Neurosciences, University of New Mexico School of Medicine, Albuquerque, NM). Full-length synaptobrevin-2 (syb) and syntaxin-1A (syx) were provided by J. E. Rothman (Department of Cell Biology, School of Medicine, Yale University, New Haven, CT). All individual SNARE proteins were subcloned into $\mathrm{pTrcHis}$ vectors to generate $\mathrm{His}_{6}$ fusion proteins. Full-length SNAP-25B and syx were subcloned into a pRSFDuet vector to generate $\mathrm{His}_{6}$-tagged t-SNARE heterodimers (Chicka et al., 2008). All GST and $\mathrm{His}_{6}$-tagged fusion proteins were expressed in Escherichia coli and purified as described previously (Liu et al., 2014).

Full-length syt-1 and chimera ${ }_{1,3}$ were subcloned into pLox Syn-DsRedSyn-GFP lentiviral vector (provided by F. Gomez-Scholl, Facultad de Medicina, Departamento de Fisiología Médica y Biofísica, Universidad de Sevilla, Sevilla, Spain) for electrophysiological recordings. Proteins were inserted with BamH1-Not1 to replace the existing DsRed, and GFP was left intact to visualize transfected cells.

Vesicle preparation. Protein-free liposomes were prepared as described previously (Liu et al., 2014). Lipid compositions were 15\% PS, 30\% PE, and 55\% PC for penetration assays; $25 \% \mathrm{PS}, 30 \% \mathrm{PE}$, and 55\% PC for 
Table 1. Hill slope and $[\text { cation }]_{1 / 2}$ for syt-1/chimera ${ }_{1,3}$-regulated fusion

\begin{tabular}{|c|c|c|}
\hline & {$[\text { cation }]_{1 / 2}(\mu \mathrm{M})$} & Hill slope \\
\hline \multicolumn{3}{|l|}{ Standard } \\
\hline \multicolumn{3}{|l|}{ Syt-1 } \\
\hline $\mathrm{Ca}^{2+}$ & $175 \pm 26$ & $2.74 \pm 0$. \\
\hline $\mathrm{Sr}^{2+}$ & $\mathrm{n} / \mathrm{a}$ & $\mathrm{n} / \mathrm{a}$ \\
\hline \multicolumn{3}{|l|}{ Chimera $_{1,3}$} \\
\hline $\mathrm{Ca}^{2+}$ & $43.3 \pm 15$ & $2.43 \pm 0.9$ \\
\hline $\mathrm{Sr}^{2+}$ & $1320 \pm 230$ & $2.48 \pm 0.7$ \\
\hline \multicolumn{3}{|l|}{ Split t-SNARE } \\
\hline \multicolumn{3}{|l|}{ Syt-1 } \\
\hline $\mathrm{Ca}^{2+}$ & $189 \pm 73$ & $1.90 \pm 0$. \\
\hline $\mathrm{Sr}^{2+}$ & $\mathrm{n} / \mathrm{a}$ & $\mathrm{n} / \mathrm{a}$ \\
\hline \multicolumn{3}{|l|}{ Chimera $_{1,3}$} \\
\hline $\mathrm{Ca}^{2+}$ & $45.2 \pm 23$ & $2.29 \pm 1$. \\
\hline $\mathrm{Sr}^{2+}$ & $1320 \pm 250$ & $3.11 \pm 1.3$ \\
\hline
\end{tabular}

Values were determined from standard and split t-SNARE in vitro fusion assays. Scatter plots of averaged data are shown in Figure $2 G, H$. Data are presented as mean \pm SEM. $N \geq 3$.

cosedimentation assays; and 25\% PS, 25\% PE, 5\% dansyl-PE, and $45 \%$ PC for stopped-flow rapid-mixing assays.

SNARE-bearing vesicles were prepared as described previously (Chicka et al., 2008). Lipid compositions for the vesicles used in the in vitro fusion assays were as follows: $15 \%$ PS, 27\% PE, 55\% PC, $1.5 \%$ NBD-PE, and $1.5 \%$ rhodamine-PE for v-SNARE vesicles; $15 \%$ PS, $30 \%$ $\mathrm{PE}$, and 55\% PC for heterodimer t-SNARE vesicles; and 25\% PS, 30\% PE, and $45 \%$ PC for syx-only t-SNARE vesicles. For coflotation assays, t-SNARE heterodimer vesicles were made from a lipid composition of $30 \% \mathrm{PE}$ and $70 \% \mathrm{PC}$.

In vitro fusion assays. Fusion, between v-SNARE vesicles and heterodimer, or syx-only t-SNARE, vesicles was monitored using a Synergy HT multidetection microplate reader (Bio-Tek) as described previously (Chicka et al., 2008; Liu et al., 2014). For standard assays, $1 \mu \mathrm{M}$ cytoplasmic domain $(\mathrm{C} 2 \mathrm{AB})$ of the indicated syt isoform or chimera was also used, and for split t-SNARE assays, $7 \mu \mathrm{M}$ soluble SNAP-25B was also used. During each run, $1 \mathrm{~mm}$ or the indicated final free [cation] was added and the reaction was monitored for an additional 60 or $120 \mathrm{~min}$. Traces were normalized to the first time point and the maximum fluorescence signal, determined from the addition of $n$-dodecyl- $\beta$-Dmaltoside, to determine the $\% F_{\max }$.

Penetration assays. The cysteine mutant forms of syt- 1 or chimera ${ }_{1,3}$ were labeled with IANBD-amide as described previously (Hui et al., 2011). NBD-labeled proteins $(0.3 \mu \mathrm{M})$ were combined with liposomes (0.1 mu total lipid) in $50 \mathrm{~mm}$ HEPES-NaOH, $100 \mathrm{~mm} \mathrm{NaCl}, \mathrm{pH} 7.4$, buffer plus $0.2 \mathrm{~mm}$ EGTA or $1 \mathrm{~mm}$ free cation. Fluorescence measurements were performed using a QM-1 fluorometer (Photon Technology International). NBD was excited at $470 \mathrm{~nm}$, and emission spectra were acquired from 490 to $630 \mathrm{~nm}$. Spectra were corrected by subtracting the background; all spectra were normalized to the signal in EGTA.

Coflotation assays. The ability of syt- 1 or chimera ${ }_{1,3}$ to bind to t-SNAREs was monitored via a coflotation assay using a Optima L-90K ultracentrifuge (Beckman Coulter), as described previously (Tucker et al., 2004). The cytoplasmic domains of syt-1 or chimera ${ }_{1,3}(10 \mu \mathrm{M})$ were incubated with PS-free t-SNARE heterodimer vesicles in the presence of $\mathrm{Ca}^{2+}$ or $\mathrm{Sr}^{2+}(1 \mathrm{~mm})$, or EGTA $(0.2 \mathrm{~mm})$. After $60 \mathrm{~min}$ at room temperature, samples were centrifuged, collected, and subjected to SDS-PAGE; gels were stained with Coomassie blue. Data were quantified using densitometry and normalized to the syx band in each lane.

Cosedimentation assays. The membrane-binding activity of the syt-1 or chimera ${ }_{1,3}$ was monitored via a cosedimentation assay using a Optima MAX-E tabletop ultracentrifuge (Beckman Coulter) as described previously (Liu et al., 2014). Data were analyzed using Prism software (GraphPad) to determine the Hill coefficients and [cation $]_{1 / 2}$ values.

Stopped-flow rapid mixing. Divalent cation regulated interactions between syt constructs and membranes were monitored via FRET using an SX.18MV stopped-flow spectrometer (Applied Photophysics) as described previously (Hui et al., 2005). Complexes were formed by mixing
$44 \mathrm{~nm}$ liposomes, $4 \mu \mathrm{M} \mathrm{C} 2 \mathrm{AB}$, and $0.2 \mathrm{~mm}$ cation, and were subsequently disassembled by rapid mixing with 2 mM EGTA. Traces were fit using the Applied Photophysics Pro Data SX software package. A single exponential function was used to determine the rate of disassembly, $k_{\text {diss }}$.

Synprint binding assay. Purified synprint $(3 \mu \mathrm{g})$ was incubated with $30 \mu \mathrm{g}$ syt- 1 or chimera ${ }_{1,3}$ GST-fusion proteins, immobilized on $30 \mu \mathrm{l}$ of glutathione Sepharose beads, as described previously (Chapman et al., 1998) and immunoblotted with anti-T7 tag mouse monoclonal antibody (1:10,000; Novagen) and a goat-anti-mouse HRP secondary antibody (1:10,000; Abcam).

Cell culture and immunostaining. All procedures were performed under the guidance of the Animal Care and Use Committee (Protocol M01221-0-06-14) at the University of Wisconsin-Madison. Hippocampal neurons from syt-1 KO mice, of either sex, were obtained at postnatal day 0 as described previously (Liu et al., 2014). The cells were infected at $5 \mathrm{~d}$ in vitro (DIV) with lentivirus, prepared in HEK293T cells as described previously (Liu et al., 2014), to express syt-1 or chimera ${ }_{13}$, and GFP.

Immunocytochemistry was performed at 14 DIV. Cells were stained with anti-syt-1 (1:500; Developmental Studies Hybridoma Bank), antisynaptophysin (1:1000; Synaptic Systems), and anti-Map2 (1:500; Millipore) antibodies, DAPI, and Alexa Fluor secondary antibodies (1:500; Life Technologies). Cells were mounted in Fluoromount (Southern Biotechnology Associates) and imaged on an FV1000 upright confocal microscope with a $60 \times, 1.4$ numerical aperture oil-immersion objective (Olympus).

Electrophysiology. At 14-18 DIV, cells were moved to a recording chamber perfused with a bath solution containing the following (in $\mathrm{mM}$ ): $128 \mathrm{NaCl}, 5 \mathrm{KCl}, 25 \mathrm{HEPES}, 30$ D-glucose, $1 \mathrm{MgCl}_{2}$, and $5 \mathrm{Ca}^{2+}$ or $\mathrm{Sr}^{2+}$, pH 7.4 (adjusted to 300-310 mOsm with D-glucose). To ensure that residual $\mathrm{Ca}^{2+}$ did not confound the $\mathrm{Sr}^{2+}$ recordings, Milli-Q water was treated with Chelex-100 resin (Bio-Rad) before use in bath solution to remove residual divalent cations. AMPA receptor currents were isolated with $20 \mu \mathrm{M}$ bicuculline (Tocris Bioscience) and $50 \mu \mathrm{M}$ D-APV (Tocris Bioscience). Borosilicate glass pipettes were pulled to a resistance of 3-5 $\mathrm{M} \Omega$ and filled with an intracellular solution containing $130 \mathrm{~mm}$ K-gluconate, 10 mM HEPES, 5 mm Na-phosphocreatine, 2 mM Mg-ATP, $1 \mathrm{~mm}$ EGTA, $5 \mu \mathrm{M}$ QX-314 (Tocris Bioscience), and $0.3 \mathrm{~mm}$ Na-GTP, $\mathrm{pH}$ 7.4. All experiments were conducted at room temperature.

Whole-cell patch-clamp recordings were made with an Axon MultiClamp 700b amplifier (Molecular Devices) in voltage-clamp mode, sampled at $10 \mathrm{kHz}$ and filtered at $2 \mathrm{kHz}$. Typical series resistances were 15 $\mathrm{M} \Omega$, with $70 \%$ of this resistance compensated, and neurons were clamped at $-70 \mathrm{mV}$. Neurons showing significant changes in series resistance over the course of recording were excluded from analysis, as were cells that exhibited a large degree of recurrent excitation that precluded analysis of EPSC kinetics. For measurement of evoked EPSCs, neurons near (within several hundred microns of) the patched (i.e., postsynaptic) cell were stimulated with a bipolar electrode in theta glass tubing. This electrode was placed directly adjacent to the soma of the presynaptic neuron. In this configuration, EPSCs from individual presynaptic cells are isolated (i.e., moving the stimulating electrode $>10$ microns away from the soma of the presynaptic neuron abolished the response). Neurons whose somata made contact with the somata of other neurons were not stimulated, to avoid evoking overlapping EPSCs from multiple presynaptic neurons. Occasional indirect or polysynaptic responses were easily identified by the lack of smooth rise and decay kinetics and were excluded from analysis. Presynaptic neurons were stimulated with $20 \mathrm{~V}$ square-wave pulses every $30 \mathrm{~s}$, and the first artifact-free EPSC (typically the first) was used for analysis. For measurement of paired-pulse facilitation, two EPSCs were evoked (with a $50 \mathrm{~ms}$ interstimulus interval) and quantified as the ratio of the second response over the first. Data were analyzed offline in Clampfit (Molecular Devices) and MATLAB (MathWorks) software. Rise and decay times were computed as $20-80 \%$ of maximum, and cumulative charge transfer functions (computed across $500 \mathrm{~ms}$ ) were fit with double exponentials to quantify fast and slow components of the charge transfer (see Fig. $5 C$ ).

For recordings of mEPSCs, $1 \mu \mathrm{M}$ TTX was added to the bath solution immediately before recording, and no series resistance compensation was used. Sixty seconds of data were analyzed for each cell. mEPSCs were 
A
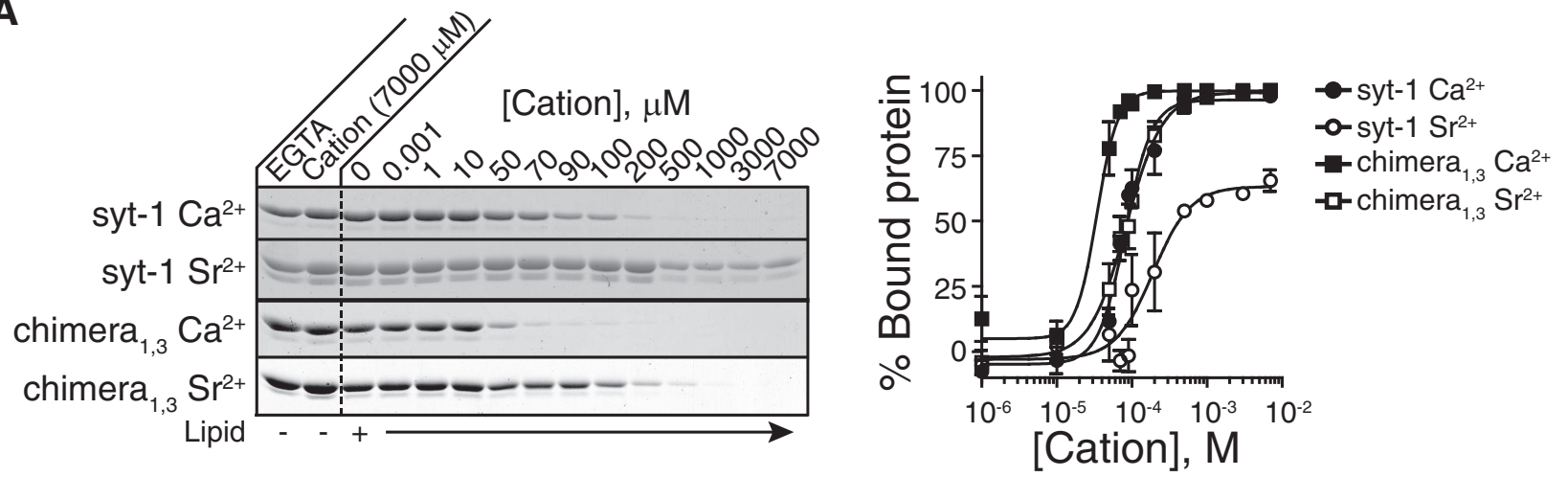

B
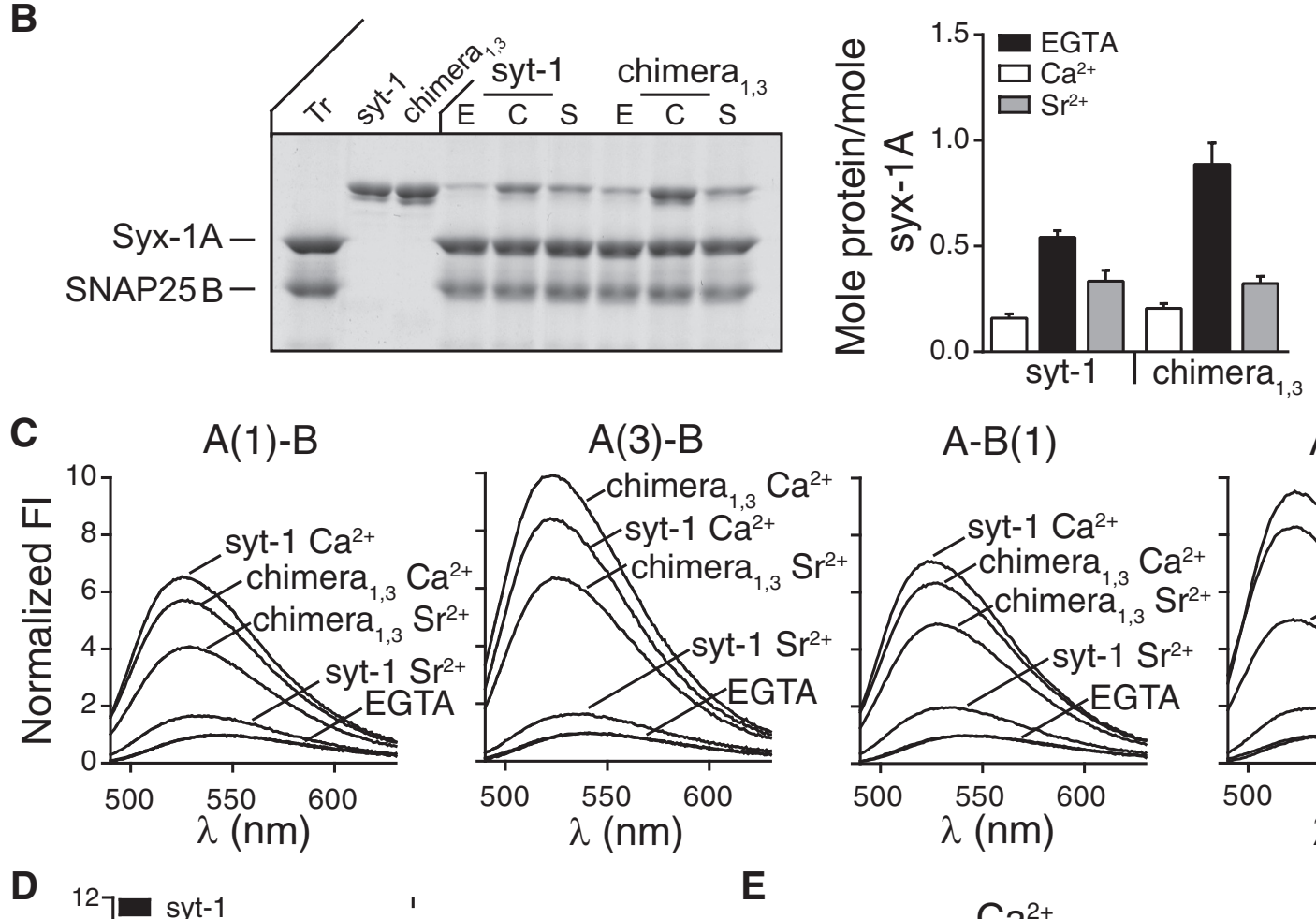

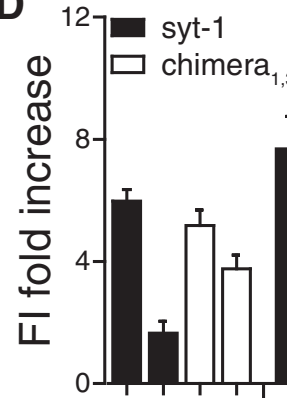

Metal: C S C S

Loop:

(1)

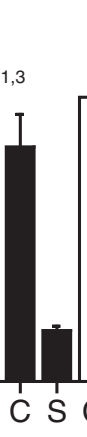

C $S$

Domain:
$\mathrm{C} 2 \mathrm{~A}$

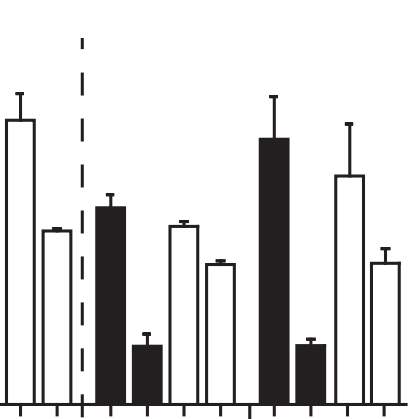

(3)
$A(3)-B$

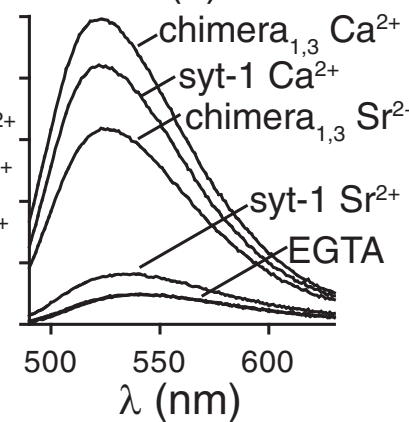

$A-B(1)$

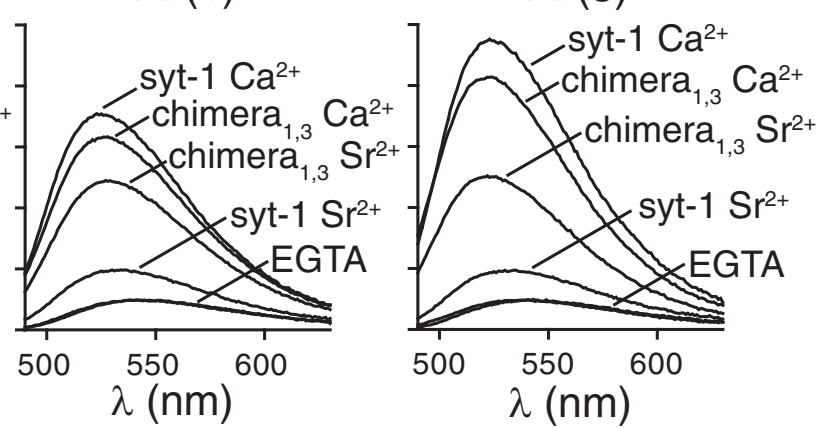

E
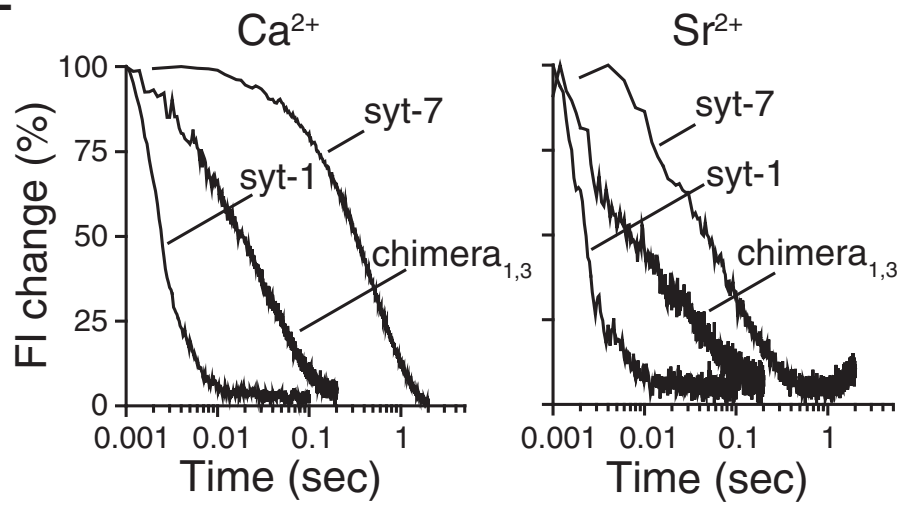

Figure 3. Chimera ${ }_{1,3}$ has altered membrane binding kinetics. $\boldsymbol{A}$, Binding of syt- 1 and chimera ${ }_{1,3}$ to liposomes was monitored via cosedimentation. Left, Representative gels showing protein depletion from the supernatant as a function of free [metal]. Right, The percentage of bound protein was calculated and used to determine the [cation $]_{1 / 2}$ and Hill coefficients for binding (Table 2 ). $N \geq 3$. B, A coflotation assay was used to measure t-SNARE binding activity of syt- 1 and chimera ${ }_{1,3}$ in the presence or absence of cation. Left, A representative gel. Right, Data were quantified and normalized to the syx signal. $N=3$. C, Membrane penetration was monitored via an environmentally sensitive fluorophore, NBD, placed in loops 1 or 3 (indicated in parentheses) in each C2 domain. Chimera $_{1,3}$ efficiently penetrated membranes in the presence of $\mathrm{Ca}^{2+}$ or $\mathrm{Sr}^{2+} . \mathrm{Ca}^{2+}$, but not $\mathrm{Sr}^{2+}$, triggered robust penetration of syt-1. Averaged spectra are shown. $\mathrm{N} \geq 4$. D, Penetration data were quantified and plotted. $\boldsymbol{E}$, Disassembly of sensor- cation-membrane complexes upon rapid mixing with EGTA. Representative traces are shown (syt- $1 k_{\text {diss }} \mathrm{Ca}^{2+}, 394 \pm 14 \mathrm{~s}^{-1} ; \mathrm{Sr}^{2+}, 327 \pm$ $28 \mathrm{~s}^{-1} ;$ syt-7 $\mathrm{k}_{\text {diss }} \mathrm{Ca}^{2+}, 2.72 \pm 0.54 \mathrm{~s}^{-1} ; \mathrm{Sr}^{2+}, 14.2 \pm 4.5 \mathrm{~s}^{-1} ;$ chimera $\left._{1,3} \mathrm{k}_{\text {diss }} \mathrm{Ca}^{2+}, 43.3 \pm 6.5 \mathrm{~s}^{-1} ; \mathrm{Sr}^{2+}, 41.7 \pm 3.7 \mathrm{~s}^{-1} ; \mathrm{N}=3\right)$. Error bars and values indicate mean $\pm \mathrm{SEM}$. E, EGTA; $\mathrm{C}, \mathrm{Ca}^{2+} ; \mathrm{S}, \mathrm{Sr}^{2+}$. 
Table 2. Hill slope and $[\text { cation }]_{1 / 2}$ for syt-1/chimera ${ }_{1,3} \cdot$ liposome interactions

\begin{tabular}{lcc}
\hline & {$[\text { cation }]_{1 / 2}(\mu \mathrm{m})$} & Hill slope \\
\hline Syt-1 & & \\
$\mathrm{Ca}^{2+}$ & $81.4 \pm 5.1$ & $2.45 \pm 0.38$ \\
$\mathrm{Sr}^{2+}$ & $191.0 \pm 54.0$ & $1.74 \pm 0.62$ \\
Chimera $_{1,3}$ & & \\
$\mathrm{Ca}^{2+}$ & $34.1 \pm 5.9$ & $3.14 \pm 0.99$ \\
$\mathrm{Sr}^{2+}$ & $84.5 \pm 6.5$ & $1.79 \pm 0.29$ \\
\hline
\end{tabular}

Values were determined from cosedimentation assays. Representative gels and percentages of bound proteins are in Figure 3A. Data are presented as mean \pm SEM. $N \geq 3$.

quantified with the Clampfit template matching algorithm and customwritten MATLAB software with a $5 \mathrm{pA}$ threshold.

Hypertonic sucrose was applied to measure the RRP of SVs (Rosenmund and Stevens, 1996; Liu et al., 2014). After patching a neuron, a second pipette containing extracellular solution, with $500 \mathrm{~mm}$ sucrose added, was positioned at the edge of the of field of view under a $40 \times$ objective (upstream of solution flow). The sucrose solution was puffed onto patched cells with a Picospritzer III (Parker Hannifin) such that all boutons contacting a given neuron were stimulated. Sucrose was applied for $10 \mathrm{~s}$, yielding a response with distinct fast and slow (steady-state) phases (see Fig. 7A). The fast component of the response was integrated to measure the RRP.

All recordings were made from a minimum of three coverslips each from three independent litters of animals. The number of cells, $N$, is indicated in the figure legends ( $N=10-20$ per condition for each electrophysiology experiment). Statistical significance was assessed with Student's $t$ tests or Mann-Whitney tests as appropriate.

\section{Results}

We first identified syt isoforms that couple $\mathrm{Sr}^{2+}$ to fusion, using a well-characterized "standard" in vitro membrane fusion assay that utilizes preassembled t-SNARE heterodimers (Fig. 1A; Tucker et al., 2004). Six isoforms were screened: syt-6, syt-7, and syt- 9 coupled both $\mathrm{Ca}^{2+}$ and $\mathrm{Sr}^{2+}$ to fusion; syt-1, syt-2, and syt- 3 were efficiently activated by $\mathrm{Ca}^{2+}$ but not $\mathrm{Sr}^{2+}$ (Fig. $1 B-G$; Bhalla et al., 2005). Because syt-7 has the slowest membrane disassembly kinetics within this family (Hui et al., 2005) and is ab- sent from SVs (Dean et al., 2012), we performed further analysis of this isoform. Syt-7 was rescreened using a more stringent variant of the fusion assay in which syt must first fold soluble SNAP25B onto syx to trigger fusion (Fig. $1 H$; Bhalla et al., 2006). In this "split" t-SNARE fusion assay, $\mathrm{Sr}^{2+}$ failed to activate syt-1 (Fig. $1 I$ ), but both metals activated syt-7 (Fig. $1 J$ ). Isothermal titration calorimetry (ITC) confirmed that syt- 1 binds one $\mathrm{Sr}^{2+}$ ion via its C2B domain (data not shown; Cheng et al., 2004). These findings might explain why $\mathrm{Sr}^{2+}$ fails to efficiently activate syt-1, as mutagenesis studies indicate the $\mathrm{C} 2 \mathrm{~B}$ domain must bind two metal $\left(\mathrm{Ca}^{2+}\right)$ ions to trigger exocytosis (Nishiki and Augustine, 2004). $\mathrm{Ca}^{2+}$-ligand mutations in $\mathrm{C} 2 \mathrm{~B}$ completely disrupt function, whereas analogous mutations in C2A have little effect (Chapman, 2008); hence, our efforts to engineer syt-1 focused on the C2B domain.

In an effort to tune the kinetics of syt-1, we replaced its metal binding loops with those of syt-7 (Fig. $2 A, B$ ). To determine which $\mathrm{C} 2$ domain of syt-7 coupled $\mathrm{Sr}^{2+}$ to fusion, both $\mathrm{C} 2 \mathrm{~A}$ and $\mathrm{C} 2 \mathrm{~B}$ were screened in a standard fusion assay. Since both $\mathrm{C} 2$ domains of syt-7 stimulated fusion in response to $\mathrm{Sr}^{2+}$ (data not shown), chimeras were constructed by grafting, individually and in combinations, the metal binding loops of either syt-7 C2A or C2B onto syt-1 C2B (Fig. 2A,B). Of these two sets of chimeras, only the proteins that harbored loops from syt-7 C2A, but not C2B (data not shown), responded to $\mathrm{Sr}^{2+}$ in the standard fusion assay (Fig. $2 C, D$ ). These four constructs, which all contained loop 3, were therefore rescreened in the split t-SNARE fusion assay and only one, chimera ${ }_{1,3}$, efficiently coupled $\mathrm{Sr}^{2+}$ to fusion (Fig. $2 E, F$ ). The cation $\left(\mathrm{Ca}^{2+}\right.$ or $\left.\mathrm{Sr}^{2+}\right)$ sensitivities were greater for chimera ${ }_{1,3}$ than for syt-1, in terms of both driving fusion (Fig. 2G,H; Table 1) and binding to membranes (Fig. $3 A$; Table 2), consistent with the higher affinity of syt-7 for metals as compared to syt-1 (Bhalla et al., 2005). Syt-1 also regulates fusion in vitro, by interacting with t-SNAREs (Bhalla et al., 2006), so we directly measured binding using PS-free heterodimer t-SNARE vesi-
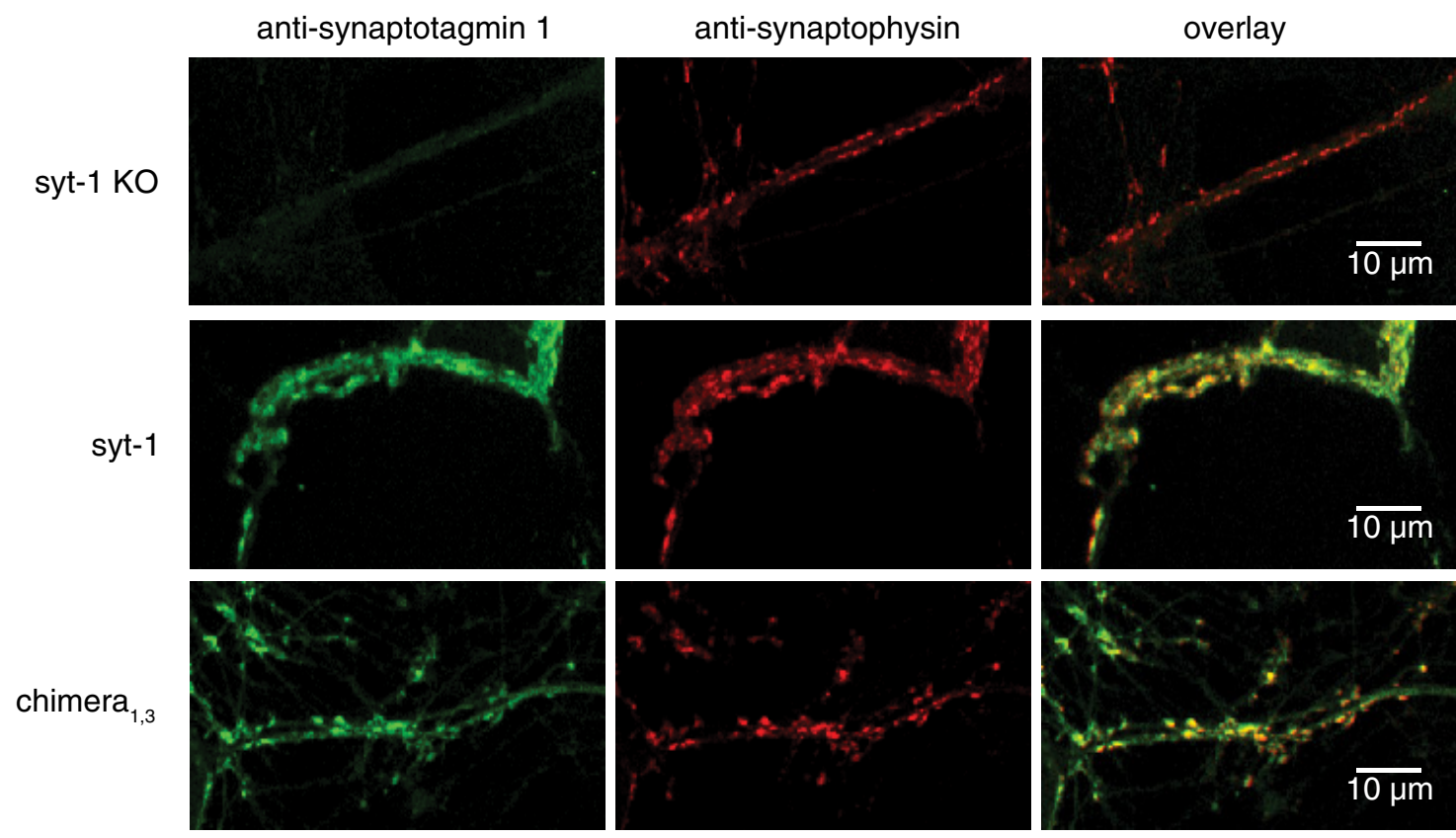

Figure 4. Chimera ${ }_{1,3}$ properly localizes to nerve terminals. The figure shows immunocytochemistry of cultured syt- 1 K0 neurons, showing the expression and synaptic localization of chimera 1,3 and syt-1. Both proteins (green) colocalize equally well with synaptophysin (red; overlay in yellow). Quantitative colocalization (Pearson's correlation coefficient) of synaptophysin did not differ $(p>0.1)$ between syt-1 and chimera ${ }_{1,3}$. 
A

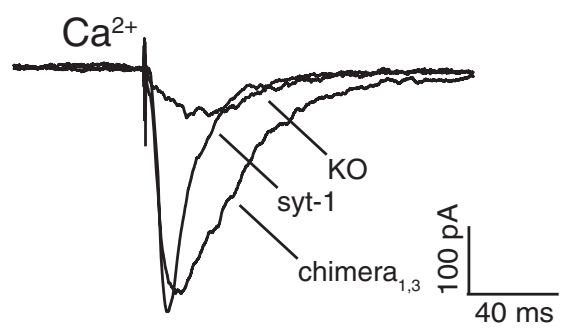

B

$$
\mathrm{Ca}^{2+}
$$

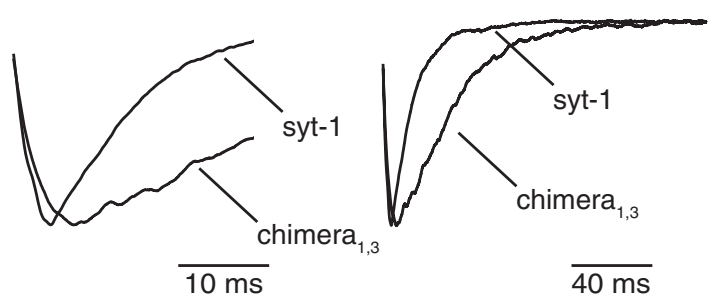

C

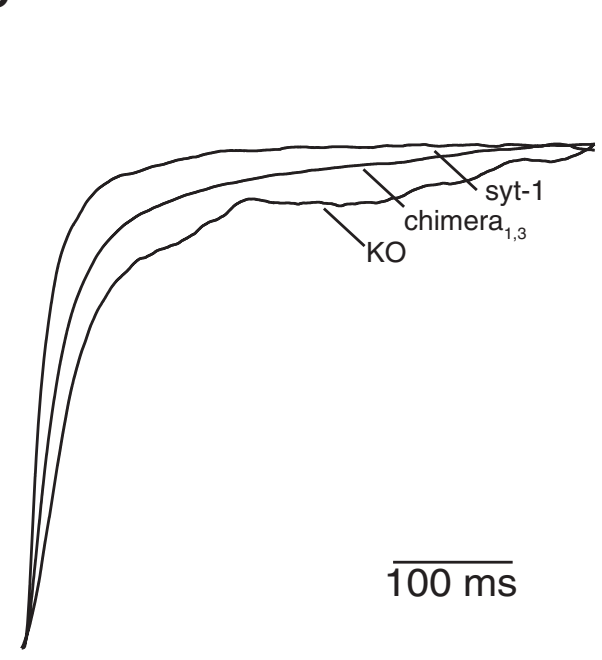

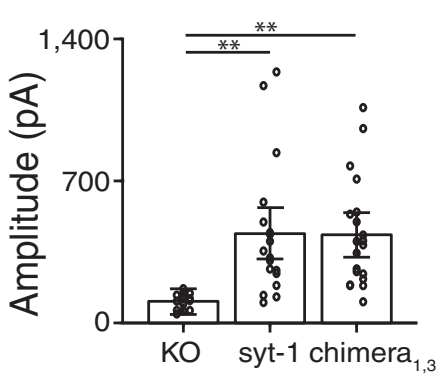
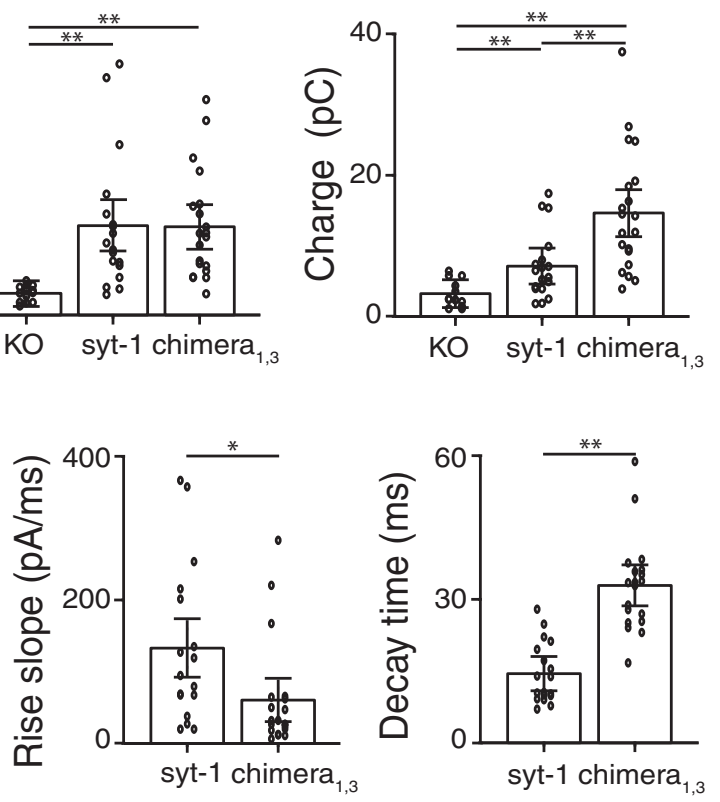
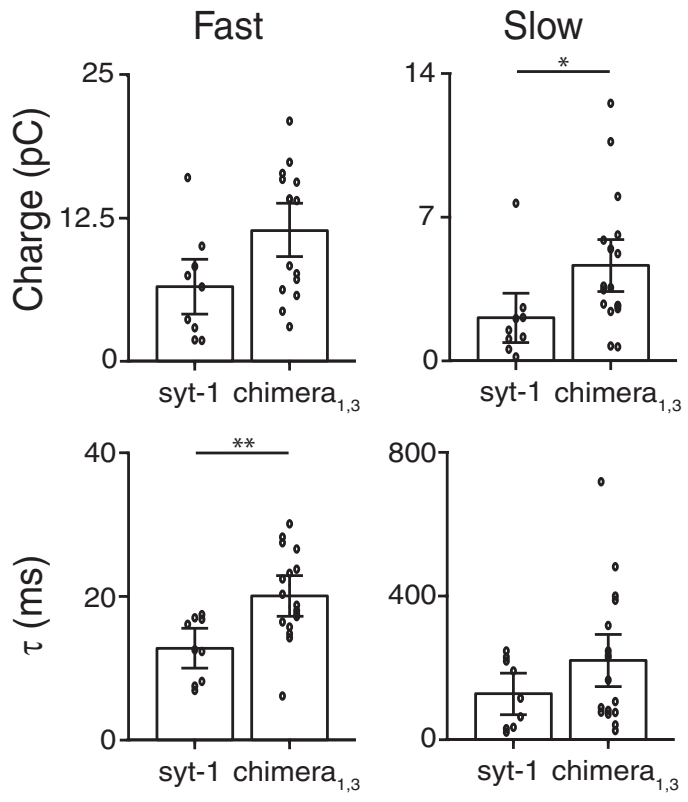

Figure 5. Chimera $a_{1,3}$ efficiently triggers glutamate release and alters the kinetics of synaptic transmission in $\mathrm{Ca}^{2+} . A, \ln \mathrm{Ca}^{2+}$, chimera ${ }_{1,3}$ rescued peak amplitude and increased total charge transfer relative to syt-1 or KO $(p<0.01)$. B. Chimera ${ }_{1,3}$ EPSCS evinced a slower rise slope $(p<0.05)$ and longer decay time $(p<0.01)$ relative to syt-1. Amplitude-normalized average EPSCs (synchronized to the rising phase) are shown on two different time scales. C, Normalized cumulative charge transfer of data from Figure $5 A$, computed across $500 \mathrm{~ms}$, in $\mathrm{Ca}^{2+}$. Analysis of synchronous and asynchronous release from neurons expressing chimera $a_{1,3}$ or syt-1 is shown. Double exponential functions were fit to the cumulative charge of each EPSC, and the amplitude and time constant $(\tau)$ of each component was quantified. Expression of chimera ${ }_{1,3}$ results in an increase in the amplitude of the slow charge component $(p<0.05)$, a nonsignificant trend toward an increase in the fast charge component $(p=.086)$, and a longer decay $\tau$ for the fast component $(p<0.01)$. Shown are traces averaged from all neurons within a condition. $N=10-20$ per condition from three or more independent litters. Error bars indicate SEM. ${ }^{*} p<0.05$; ${ }^{* *} p<0.01$.

cles. In the presence of $\mathrm{Ca}^{2+}$, chimera ${ }_{1,3}$ bound more efficiently than syt-1; in $\mathrm{Sr}^{2+}$, no differences were observed (Fig. $3 B)$. It should be noted, however, that the relevance of this interaction during secretion from cells remains the subject of debate (Zhang et al., 2002, 2010).

Upon binding $\mathrm{Ca}^{2+}$, metal binding loops 1 and 3, from each C2 domain of syt-1, penetrate membranes, with a small contribution from loop 2 (Hui et al., 2011). To monitor penetration, loops 1 and 3 , were individually labeled with an environmentally sensitive fluo- rophore, NBD. In the presence of $\mathrm{Ca}^{2+}$, all labeled loops of syt-1 penetrated membranes. However, $\mathrm{Sr}^{2+}$ failed to trigger efficient penetration (Fig. 3C,D). Importantly, both $\mathrm{C} 2$ domains of chimera $_{1,3}$ efficiently penetrated membranes in the presence of either $\mathrm{Ca}^{2+}$ or $\mathrm{Sr}^{2+}$ (Fig. 3C,D). These results support the emerging view that membrane penetration by syt-1 is a crucial step in $\mathrm{Ca}^{2+}$. triggered membrane fusion (Paddock et al., 2011; Liu et al., 2014) and provide an explanation as to why $\mathrm{Sr}^{2+}$ drives synaptic transmission less efficiently than $\mathrm{Ca}^{2+}$. Interestingly, although the C2A do- 
A

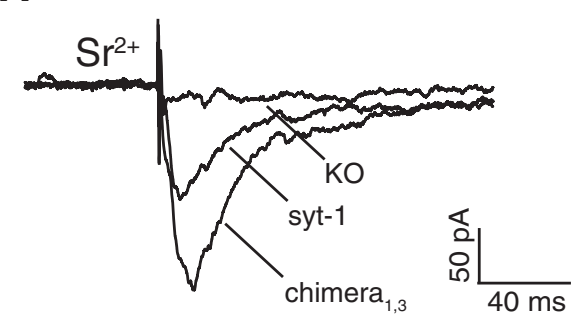

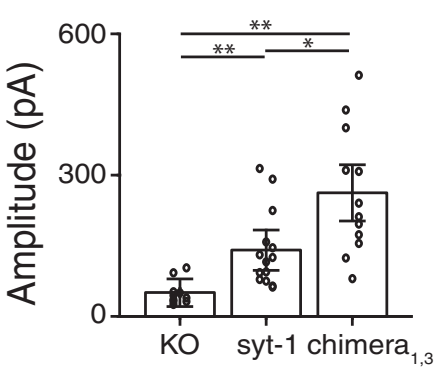

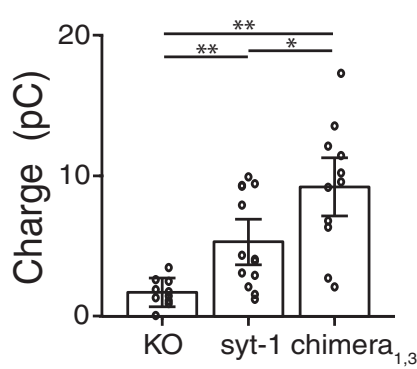

B
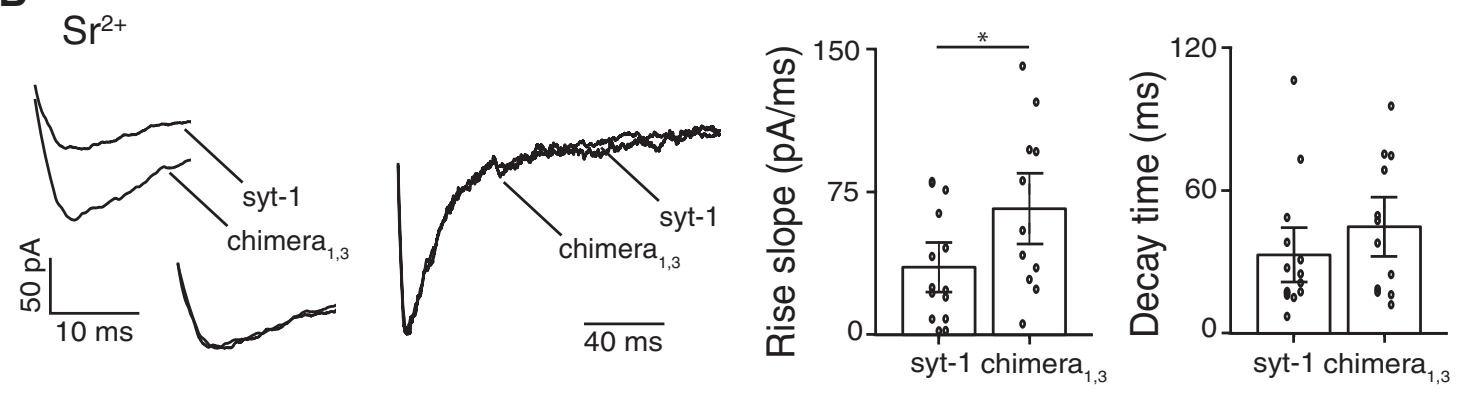

Figure 6. Chimera $a_{1,3}$ supports robust synchronous transmission in $\mathrm{Sr}^{2+} . A, \operatorname{In~Sr}^{2+}$, chimera 1,3 increased charge transfer and amplitude relative to syt-1 ( $\left.p<0.05\right)$. K0s showed little release. $B_{1}$, Chimera ${ }_{1,3}$ EPSCs showed a steeper, faster rise slope $(p<0.05)$. No differences in decay kinetics were observed in $\mathrm{Sr}^{2+}$. Shown are traces averaged from all neurons within a condition. $N=$ $10-20$ per condition from three or more independent litters. Error bars indicate SEM. ${ }^{*} p<0.05 ;{ }^{* *} p<0.01$.

main of chimera ${ }_{1,3}$ was not engineered to bind $\mathrm{Sr}^{2+}$, it efficiently penetrated membranes (Fig. 3C,D); ITC was not possible with this construct. So, either an active $\mathrm{C} 2 \mathrm{~B}$ domain "pulls" C2A into the bilayer, or $\mathrm{C} 2 \mathrm{~A}$ is activated via contact with the engineered $\mathrm{C} 2 \mathrm{~B}$ domain (Bai et al., 2002; Liu et al., 2014).

To determine whether these alterations in syt-1 led to changes in membrane interactions, we performed stopped-flow rapidmixing experiments. To mimic the decay of $\mathrm{Ca}^{2+}$ transients in nerve terminals, sensor-cation-membrane complexes were rapidly mixed with excess chelator. In $\mathrm{Ca}^{2+}$, chimera ${ }_{1,3}$ disassembled much more slowly than syt-1 (Fig. 3E, left), a point we return to below. Similarly, the disassembly rates of chimera ${ }_{1,3}$ were slower in $\mathrm{Sr}^{2+}$ than syt-1 (Fig. 3E, right).

To determine whether chimera ${ }_{1,3}$ can change the rate of neurotransmitter release, we expressed it, or syt-1, in dissociated hippocampal neurons derived from syt-1 KO mice. Both proteins were properly localized to nerve terminals, as colocalization (Pearson's correlation coefficient) with synaptophysin did not differ ( $p>0.1$; Fig. 4). The number of synapses (quantified as the number of synaptophysin puncta) also did not differ across conditions ( $p>0.1$; data not shown).

We performed patch clamp recordings of EPSCs in the presence of $5 \mathrm{mM} \mathrm{Ca}^{2+}$ or $\mathrm{Sr}^{2+}$. Individual EPSCs were evoked with a bipolar electrode positioned near the soma of a nearby cell. Approximately $60 \%$ of stimulated neurons had monosynaptic connections with the patched (postsynaptic) neuron, and this did not differ across conditions ( $p>0.1$; data not shown). The characteristics of these EPSCs were comparable to what has been found previously in this preparation (Liu et al., 2009, 2014; Yao et al., 2011).

Chimera $_{1,3}$ did not simply rescue rapid evoked release, but exhibited a gain-of-function relative to syt-1. In the presence of $\mathrm{Ca}^{2+}$, chimera ${ }_{1,3}$ increased the total charge transfer without altering the peak current (Fig. $5 A$; chimera $_{1,3}$ charge, $14.66 \pm 1.94$ pC; syt-1 charge, $7.12 \pm 1.10 \mathrm{pC} ; p<0.01 ; N=10-20$ per condition). Importantly, in $\mathrm{Ca}^{2+}$, chimera ${ }_{1,3}$ yielded a slower rise of evoked release (Fig. $5 B$; chimera $_{1,3}$ rise slope, $60.48 \pm 16.8$
$\mathrm{pA} / \mathrm{ms}$; syt-1 rise slope, $132.9 \pm 26.7 \mathrm{pA} / \mathrm{ms} ; p<0.05)$ and a decay time twice as long as that of neurons expressing syt-1 (Fig.

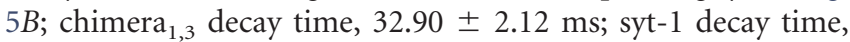
$14.45 \pm 1.49 \mathrm{~ms} ; p<0.01 ; N=10-20$ per condition). When cumulative charge transfers were fit with double exponential functions, we found that EPSC decays of neurons expressing chimera $_{1,3}$ had a significantly larger slow component of release (Fig. $5 C$; $_{\text {chimera }}{ }_{1,3}$ slow charge amplitude, $4.45 \pm 0.79 \mathrm{pC}$; syt- 1 slow charge amplitude, $2.09 \pm 0.74 \mathrm{pC} ; p<0.05)$, and the time constant $(\tau)$ of the fast component was significantly lengthened (Fig. $5 C$; chimera $_{1,3}$ fast charge $\tau, 20.1 \pm 1.49 \mathrm{~ms}$; syt-1 fast charge $\tau$, $12.8 \pm 1.45 \mathrm{~ms} ; p<0.01)$. Hence, grafting the loops of the slowest syt isoform, syt-7 (Hui et al., 2005), onto syt-1 slows the kinetics of synaptic transmission.

A key finding was that in $\mathrm{Sr}^{2+}$, chimera ${ }_{1,3}$ significantly increased both the total charge transfer and peak current relative to syt- 1 (Fig. $6 A$; chimera $_{1,3}$ charge, $9.21 \pm 1.37$ pC; syt-1 charge, $5.94 \pm 1.06 \mathrm{pC} ; p<0.05$; chimera ${ }_{1,3}$ amplitude, $262.5 \pm 38.5$ pA; syt- 1 amplitude, $141.0 \pm 21.7$ pA; $p<0.05$; $N=10-20$ per condition). In neurons expressing chimera $_{1,3}$, the rising phase of the EPSC in $\mathrm{Sr}^{2+}$ was steeper than in cells expressing syt-1 (Fig. $6 B$; $^{\text {chimera }}{ }_{1,3}$ rise slope, $66.17 \pm 13.3$ $\mathrm{pA} / \mathrm{ms}$; syt- 1 rise slope, $35.49 \pm 7.76 \mathrm{pA} / \mathrm{ms} ; p<0.05)$. There were no observable differences in the decay phase of EPSCs regulated by chimera ${ }_{1,3}$ and syt-1 in $\mathrm{Sr}^{2+}$ (Fig. $6 \mathrm{~B}$ ), presumably because of the slow rate (seconds) at which $\mathrm{Sr}^{2+}$ is cleared from nerve terminals (Xu-Friedman and Regehr, 2000; Babai et al., 2014). As such, EPSC decays in $\mathrm{Sr}^{2+}$ were not analyzed further. Consistent with previous reports, $\mathrm{Sr}^{2+}$ was ineffective at triggering release in syt-1 KO neurons (Fig. 6A; Shin et al., 2003; Babai et al., 2014), indicating that any remaining $\mathrm{Ca}^{2+}$ sensors do not efficiently sense $\mathrm{Sr}^{2+}$.

It should be noted that the increase in charge transfer could in principal be due to an increase in the size of the readily-releasable pool (RRP) of vesicles (Rosenmund and Stevens, 1996), rather than an effect on the release machinery during the final stages of exocytosis. To address this, we measured the RRP in KO, syt-1, and 
A $\mathrm{Ca}^{2+}$

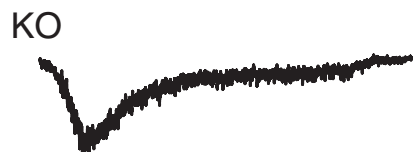

syt-1
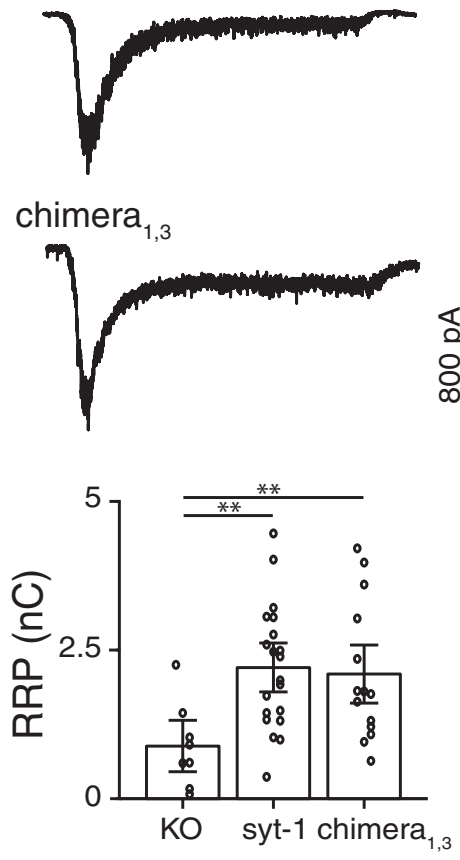

$\mathrm{Sr}^{2+}$

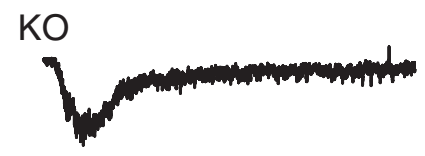

syt-1
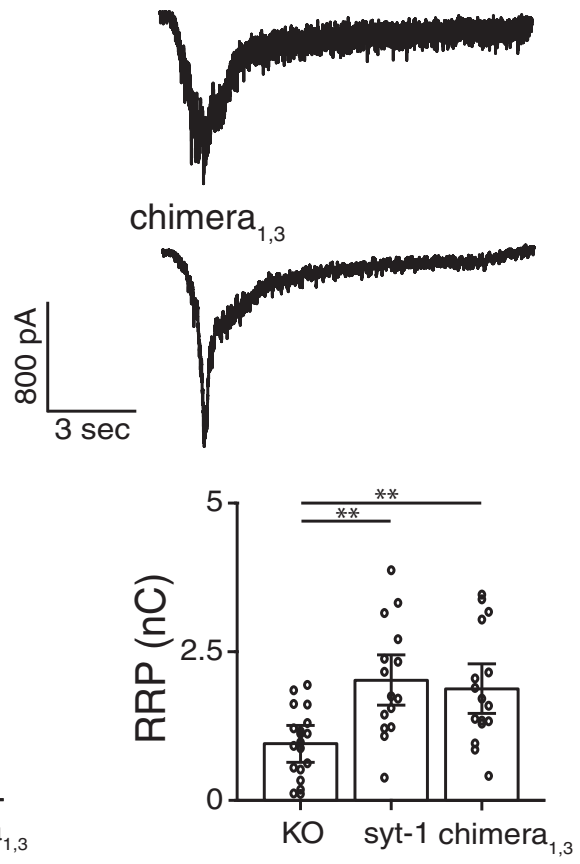

B

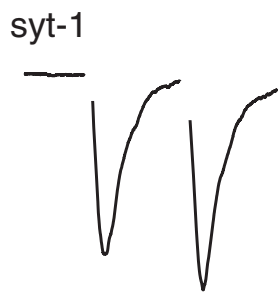

chimera $_{1,3}$
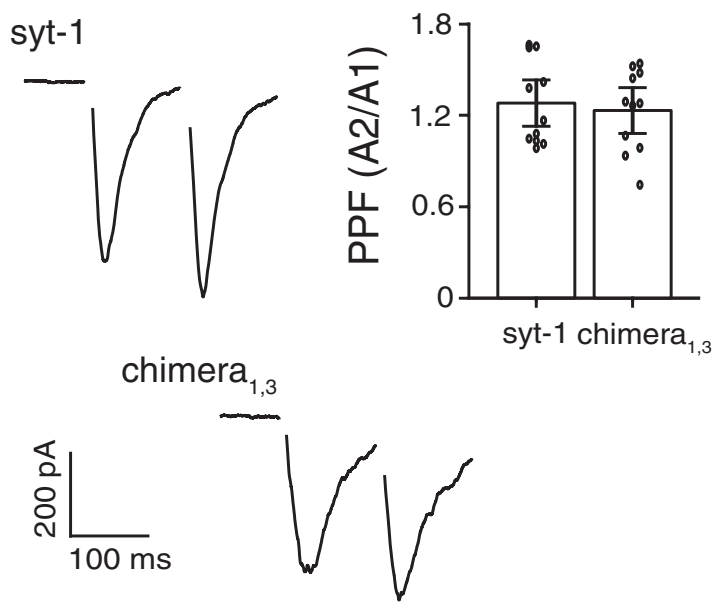

C

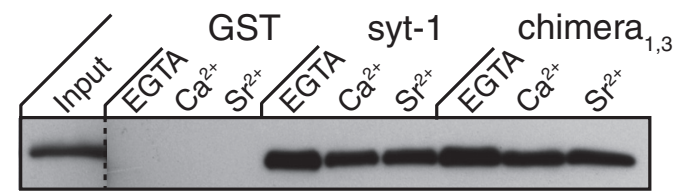

Figure 7. Chimera ${ }_{1,3}$ rescues the readily releasable pool of SVs and exhibits normal paired-pulse facilitation (PPF) and synprint binding activity. $\boldsymbol{A}$, Chimera ${ }_{1,3}$ and syt-1 yielded equivalent RRPs, as measured using hypertonic sucrose, in $\mathrm{Ca}^{2+}$ (left) and $\mathrm{Sr}^{2+}$ (right). The RRP was reduced in KO neurons in both metals. Representative traces are shown; $N=9-20$ per condition from three or more independent litters. $\boldsymbol{B}$, Left, Average responses evoked by paired pulses ( $50 \mathrm{~ms}$ interstimulus interval) measured from neurons expressing syt- 1 or chimera ${ }_{1,3}$. Right, Paired-pulse facilitation (quantified as the amplitude of the second response over the first) did not differ between conditions. $N=11$ per condition. $C$, Binding of the synprint peptide to syt- 1 and chimera ${ }_{1,3}$ immobilized as GST fusion proteins. A representative immunoblot is shown. No differences were observed. GST was used as a negative control; $N=3$. Error bars indicate SEM. ${ }^{* *} p<0.01$.

chimera ${ }_{1,3}$-expressing neurons with hypertonic sucrose. We found that chimera ${ }_{1,3}$ rescued the size of the RRP as efficiently as syt-1 in either $\mathrm{Ca}^{2+}$ (Fig. 7A, left panels) or $\mathrm{Sr}^{2+}$ (right panels). To the best of our knowledge, these experiments provide the first example of a mutant form of syt- 1 that alters the kinetics of functional synaptic transmission (i.e., without impairing the RRP).

Because overexpression of wild-type and mutant forms of syt do not alter $\mathrm{Ca}^{2+}$ entry (Wang et al., 2001; Young and Neher, 2009), it is unlikely that our kinetic effects are due to changes in metal influx. Nonetheless, we examined paired-pulse facilitation, a form of short-term plasticity sensitive to changes in presynaptic $\mathrm{Ca}^{2+}$ dynamics (Fioravante and Regehr, 2011). The paired-pulse ratio was similar between neurons expressing syt- 1 and chimera ${ }_{1,3}$ (Fig. $7 B$ ). Moreover, the ability of chimera ${ }_{1,3}$ to bind synprint, the $\mathrm{Ca}^{2+}$ channel domain that mediates interactions with the release machinery (Sheng et al., 1997), was indistinguishable from that of syt-1 (Fig. 7C). Collectively, these results argue against the kinetic effects in Figure 6 being due to an alteration in the coupling of release machinery to $\mathrm{Ca}^{2+}$ channels.

Finally, recordings of "mini" excitatory currents (mEPSCs), reflecting spontaneous release of individual SVs, showed no difference in amplitude or kinetics among conditions (Fig. 8), arguing against a postsynaptic effect. Loss of syt-1 results in an increase in the frequency of mEPSCs, suggesting that syt- 1 has a second function as a fusion clamp (Chicka et al., 2008; Liu et al., 2014). Interestingly, chimera ${ }_{1,3}$ failed to clamp minis, showing a frequency equivalent to KO (Fig. 8B). Thus, metal binding loops 1 and 3 of syt-1 C2B not only govern the kinetics of evoked release, but also play roles in suppressing spontaneous transmission.

\section{Discussion}

Upon binding $\mathrm{Ca}^{2+}$, syt-1 penetrates membranes that harbor anionic phospholipids (Chapman and Davis, 1998; Chapman, 2008). In a reconstituted system, syt-1 preferentially penetrated t-SNAREbearing membranes to accelerate fusion (Bai et al., 2004; Chicka et al., 2008). Moreover, the abilities of mutant forms of syt-1 to penetrate membranes was correlated with their abilities to drive synchronous synaptic transmission in cultured neurons (Liu et al., 2014). This latter finding suggests that membrane penetration constitutes an essential step in excitationsecretion coupling. The work presented here provides a more direct demonstration that penetration by syt-1 is a key step in SV exocytosis. Specifically, we used a 
A KO
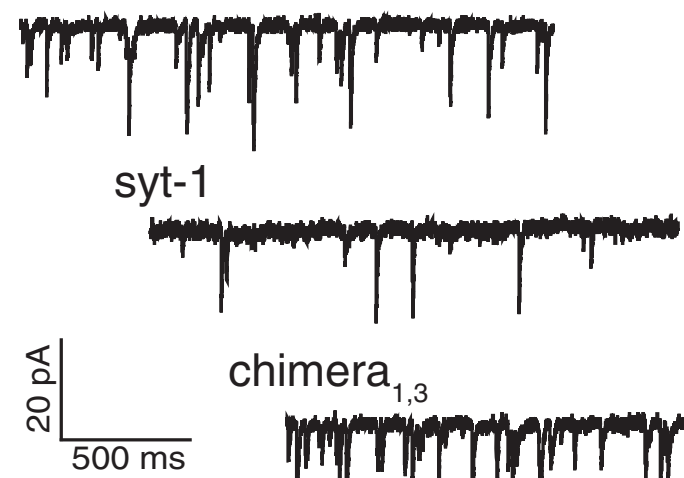

$$
\text { chimera }_{1,3}
$$

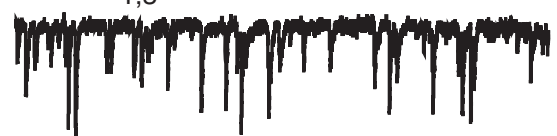

B

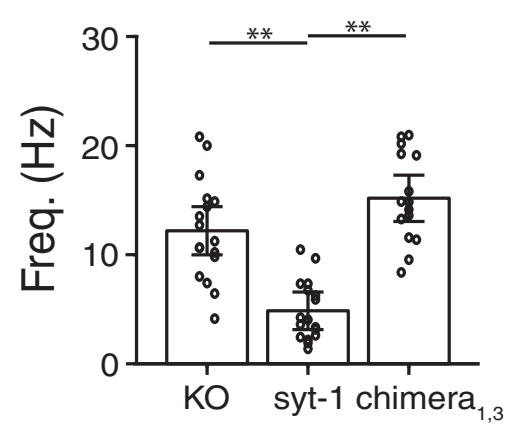

C

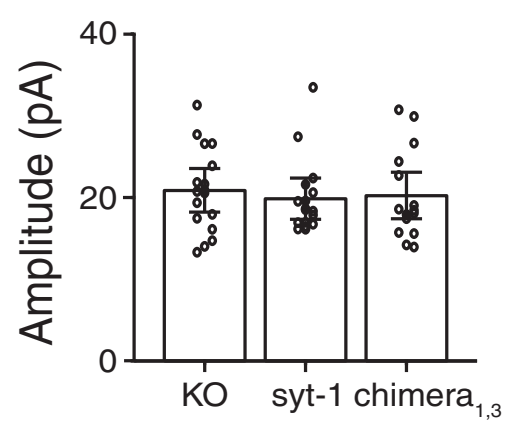

Figure 8. Chimera ${ }_{1,3}$ fails to clamp spontaneous vesicle exocytosis. $\boldsymbol{A}$, Spontaneous $\mathrm{mEPSC}$ recorded from K0, syt-1, and chimera $_{1,3}$ neurons. Averaged mEPSC waveforms for each condition are shown on the right. $\boldsymbol{B}$, Chimera , $_{1,3}$ failed to clamp the increase in mEPSC frequency characteristic of the KO neurons; syt-1 efficiently clamped minis. C, Amplitude of mEPSCs did not differ across conditions. $N=15-20$ per condition from three or more independent litters of animals. Error bars indicate SEM. ${ }^{* *} p<$ 0.01 .

chemical genetic approach to engineer syt-1 to respond to a nonphysiological metal, $\mathrm{Sr}^{2+}$. In the presence of $\mathrm{Sr}^{2+}$, syt-1 binds membranes (Fig. 3A), but fails to penetrate (Fig. 3C,D), and so only weakly triggers exocytosis in neurons (Fig. 6A). In contrast, chimera $_{1,3}$ bound (Fig. $3 A$ ) and penetrated membranes (Fig. $3 C, D)$ in response to $\mathrm{Sr}^{2+}$, resulting in robust synchronous neurotransmitter release (Fig. $6 \mathrm{~A}$ ). These results prompt the question as to whether the kinetics of the crucial interaction between syt-1 and membranes affect the time course of synaptic transmission.

EPSC decays are governed by a myriad of presynaptic and postsynaptic mechanisms, including presynaptic action potential waveform (Taschenberger and von Gersdorff, 2000), AMPA receptor desensitization (Wall et al., 2002), and clearance of glutamate from the synaptic cleft (Takahashi et al., 1995). The effects reported here reveal a novel factor that determines the kinetics of transmission, namely, chimera ${ }_{1,3}$ slowed the sensor-membrane disassembly rate upon chelation of $\mathrm{Ca}^{2+}$ (Fig. 3E, left) and also slowed the rate at which EPSCs decay (Fig. $5 B, C$ ). Once activated by metal, the chimera "holds onto" membranes longer, thus widening the window in which vesicles can fuse. It is unlikely that these kinetic changes are the result of changes in $\mathrm{Ca}^{2+}$ affinity, as it has been shown that simply increasing the affinity of syt- 1 for $\mathrm{Ca}^{2+}$ does not alter the time course of transmission (Rhee et al., 2005). Rather, the longer EPSC decays reported here likely reflect longer-lived sensor-membrane complexes that continue to drive release. Thus, we propose that the decay phase of EPSCs are governed, in part, by the dwell time of syt-1-membrane complexes.

Previous work has shown that syt-1 KO neurons exhibit a significantly enhanced rate of spontaneous "miniature" release

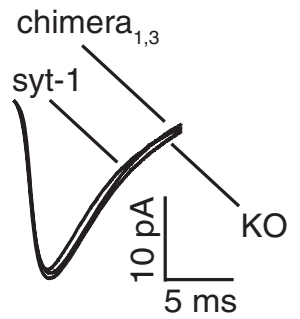

(DiAntonio and Schwarz, 1994; Littleton et al., 1994; Liu et al., 2009). This led to the suggestion that during basal (i.e., low $\mathrm{Ca}^{2+}$ ) conditions, syt-1 reduces the rate of spontaneous fusion by serving as a "clamp," either by inhibiting SNARE assembly directly (Chicka et al., 2008) or by inhibiting a second $\mathrm{Ca}^{2+}$ sensor (Xu et al., 2009; Kochubey and Schneggenburger, 2011). Interestingly, while chimera ${ }_{1,3}$ was able to efficiently trigger evoked exocytosis, it failed to rescue this clamping function of syt-1. The mechanism of this clamping function is unclear, because it can be disrupted by mutating either the metal/membrane binding loops (the present work) or the linker connecting the two C2 domains of syt-1 (Liu et al., 2014). It should also be noted that spontaneous release appears to involve a somewhat distinct pool of SVs (Kavalali, 2015), so the differential regulation of these two modes of release likely involves numerous other factors.

Finally, during synaptic transmission, chimera $_{1,3}$ restored the total charge transfer in $\mathrm{Sr}^{2+}$ (Fig. 6A) to levels comparable to syt-1 in $\mathrm{Ca}^{2+}$ (Fig. 5A), demonstrating the functionality of this engineered sensor. Future work will use this chimera as a tool to dissect aspects of syt- 1 function from other $\mathrm{Ca}^{2+}$ triggered processes in nerve terminals (e.g., in the context of spontaneous release), and will take advantage of its unique kinetic properties to probe the effect of glutamate release rates on network behavior.

\section{References}

Babai N, Kochubey O, Keller D, Schneggenburger R (2014) An alien divalent ion reveals a major role for $\mathrm{Ca}(2)(+)$ buffering in controlling slow transmitter release. J Neurosci 34:12622-12635. CrossRef Medline

Bai J, Wang P, Chapman ER (2002) C2A activates a cryptic $\mathrm{Ca}(2+)$ triggered membrane penetration activity within the $\mathrm{C} 2 \mathrm{~B}$ domain of synaptotagmin I. Proc Natl Acad Sci U S A 99:1665-1670. CrossRef Medline

Bai J, Tucker WC, Chapman ER (2004) PIP2 increases the speed of response of synaptotagmin and steers its membrane-penetration activity toward the plasma membrane. Nat Struct Mol Biol 11:36-44. CrossRef Medline

Bhalla A, Tucker WC, Chapman ER (2005) Synaptotagmin isoforms couple distinct ranges of $\mathrm{Ca} 2+, \mathrm{Ba} 2+$, and $\mathrm{Sr} 2+$ concentration to SNAREmediated membrane fusion. Mol Biol Cell 16:4755-4764. CrossRef Medline

Bhalla A, Chicka MC, Tucker WC, Chapman ER (2006) Ca(2+)synaptotagmin directly regulates t-SNARE function during reconstituted membrane fusion. Nat Struct Mol Biol 13:323-330. CrossRef Medline

Bhalla A, Chicka MC, Chapman ER (2008) Analysis of the synaptotagmin family during reconstituted membrane fusion. Uncovering a class of inhibitory isoforms. J Biol Chem 283:21799-21807. CrossRef Medline

Brose N, Petrenko AG, Südhof TC, Jahn R (1992) Synaptotagmin: a calcium sensor on the synaptic vesicle surface. Science 256:1021-1025. CrossRef Medline

Chapman ER (2008) How does synaptotagmin trigger neurotransmitter release? Annu Rev Biochem 77:615-641. CrossRef Medline

Chapman ER, Davis AF (1998) Direct interaction of a Ca2+-binding loop of synaptotagmin with lipid bilayers. J Biol Chem 273:13995-14001. CrossRef Medline

Chapman ER, Desai RC, Davis AF, Tornehl CK (1998) Delineation of the oligomerization, AP-2 binding, and synprint binding region of the $\mathrm{C} 2 \mathrm{~B}$ 
domain of synaptotagmin. J Biol Chem 273:32966-32972. CrossRef Medline

Cheng Y, Sequeira SM, Malinina L, Tereshko V, Söllner TH, Patel DJ (2004) Crystallographic identification of $\mathrm{Ca} 2+$ and $\mathrm{Sr} 2+$ coordination sites in synaptotagmin I C2B domain. Protein Sci 13:2665-2672. Medline

Chicka MC, Hui E, Liu H, Chapman ER (2008) Synaptotagmin arrests the SNARE complex before triggering fast, efficient membrane fusion in response to Ca2+. Nat Struct Mol Biol 15:827-835. CrossRef Medline

Dean C, Dunning FM, Liu H, Bomba-Warczak E, Martens H, Bharat V, Ahmed S, Chapman ER (2012) Axonal and dendritic synaptotagmin isoforms revealed by a pHluorin-syt functional screen. Mol Biol Cell 23: 1715-1727. CrossRef Medline

DiAntonio A, Schwarz TL (1994) The effect on synaptic physiology of synaptotagmin mutations in Drosophila. Neuron 12:909-920. CrossRef Medline

Fioravante D, Regehr WG (2011) Short-term forms of presynaptic plasticity. Curr Opin Neurobiol 21:269-274. CrossRef Medline

Fuson KL, Montes M, Robert JJ, Sutton RB (2007) Structure of human synaptotagmin $1 \mathrm{C} 2 \mathrm{AB}$ in the absence of $\mathrm{Ca} 2+$ reveals a novel domain association. Biochemistry 46:13041-13048. CrossRef Medline

Geppert M, Goda Y, Hammer RE, Li C, Rosahl TW, Stevens CF, Südhof TC (1994) Synaptotagmin I: a major Ca2 + sensor for transmitter release at a central synapse. Cell 79:717-727. CrossRef Medline

Goda Y, Stevens CF (1994) Two components of transmitter release at a central synapse. Proc Natl Acad Sci U S A 91:12942-12946. CrossRef Medline

Hui E, Bai J, Wang P, Sugimori M, Llinas RR, Chapman ER (2005) Three distinct kinetic groupings of the synaptotagmin family: candidate sensors for rapid and delayed exocytosis. Proc Natl Acad Sci U S A 102:52105214. CrossRef Medline

Hui E, Gaffaney JD, Wang Z, Johnson CP, Evans CS, Chapman ER (2011) Mechanism and function of synaptotagmin-mediated membrane apposition. Nat Struct Mol Biol 18:813-821. CrossRef Medline

Kavalali ET (2015) The mechanisms and functions of spontaneous neurotransmitter release. Nat Rev Neurosci 16:5-16. Medline

Kochubey O, Schneggenburger R (2011) Synaptotagmin increases the dynamic range of synapses by driving $\mathrm{Ca}(2)+$-evoked release and by clamping a near-linear remaining $\mathrm{Ca}(2)+$ sensor. Neuron 69:736-748. CrossRef Medline

Lau PM, Bi GQ (2005) Synaptic mechanisms of persistent reverberatory activity in neuronal networks. Proc Natl Acad Sci U S A 102:1033310338. CrossRef Medline

Littleton JT, Stern M, Perin M, Bellen HJ (1994) Calcium dependence of neurotransmitter release and rate of spontaneous vesicle fusions are altered in Drosophila synaptotagmin mutants. Proc Natl Acad Sci U S A 91:10888-10892. CrossRef Medline

Liu H, Dean C, Arthur CP, Dong M, Chapman ER (2009) Autapses and networks of hippocampal neurons exhibit distinct synaptic transmission phenotypes in the absence of synaptotagmin I. J Neurosci 29:7395-7403. CrossRef Medline

Liu H, Bai H, Xue R, Takahashi H, Edwardson JM, Chapman ER (2014) Linker mutations reveal the complexity of synaptotagmin 1 action during synaptic transmission. Nat Neurosci 17:670-677. CrossRef Medline

Mackler JM, Drummond JA, Loewen CA, Robinson IM, Reist NE (2002) The $\mathrm{C}(2) \mathrm{B} \mathrm{Ca}(2+)$-binding motif of synaptotagmin is required for synaptic transmission in vivo. Nature 418:340-344. CrossRef Medline

Matthew WD, Tsavaler L, Reichardt LF (1981) Identification of a synaptic vesicle-specific membrane protein with a wide distribution in neuronal and neurosecretory tissue. J Cell Biol 91:257-269. CrossRef Medline

Nishiki T, Augustine GJ (2004) Dual roles of the C2B domain of synaptotagmin I in synchronizing $\mathrm{Ca} 2+$-dependent neurotransmitter release. J Neurosci 24:8542-8550. CrossRef Medline
Paddock BE, Wang Z, Biela LM, Chen K, Getzy MD, Striegel A, Richmond JE, Chapman ER, Featherstone DE, Reist NE (2011) Membrane penetration by synaptotagmin is required for coupling calcium binding to vesicle fusion in vivo. J Neurosci 31:2248-2257. CrossRef Medline

Perin MS, Fried VA, Mignery GA, Jahn R, Südhof TC (1990) Phospholipid binding by a synaptic vesicle protein homologous to the regulatory region of protein kinase C. Nature 345:260-263. CrossRef Medline

Rhee JS, Li LY, Shin OH, Rah JC, Rizo J, Südhof TC, Rosenmund C (2005) Augmenting neurotransmitter release by enhancing the apparent $\mathrm{Ca} 2+$ affinity of synaptotagmin 1. Proc Natl Acad Sci U S A 102:18664-18669. CrossRef Medline

Rosenmund C, Stevens CF (1996) Definition of the readily releasable pool of vesicles at hippocampal synapses. Neuron 16:1197-1207. CrossRef Medline

Rumpel E, Behrends JC (1999) Sr2+-dependent asynchronous evoked transmission at rat striatal inhibitory synapses in vitro. J Physiol 514:447458. CrossRef Medline

Sheng ZH, Yokoyama CT, Catterall WA (1997) Interaction of the synprint site of $\mathrm{N}$-type $\mathrm{Ca} 2+$ channels with the $\mathrm{C} 2 \mathrm{~B}$ domain of synaptotagmin I. Proc Natl Acad Sci U S A 94:5405-5410. CrossRef Medline

Shin OH, Rhee JS, Tang J, Sugita S, Rosenmund C, Südhof TC (2003) Sr2+ binding to the $\mathrm{Ca} 2+$ binding site of the synaptotagmin $1 \mathrm{C} 2 \mathrm{~B}$ domain triggers fast exocytosis without stimulating SNARE interactions. Neuron 37:99-108. CrossRef Medline

Takahashi M, Kovalchuk Y, Attwell D (1995) Pre- and postsynaptic determinants of EPSC waveform at cerebellar climbing fiber and parallel fiber to Purkinje cell synapses. J Neurosci 15:5693-5702. Medline

Taschenberger H, von Gersdorff H (2000) Fine-tuning an auditory synapse for speed and fidelity: developmental changes in presynaptic waveform, EPSC kinetics, and synaptic plasticity. J Neurosci 20:9162-9173. Medline

Tucker WC, Weber T, Chapman ER (2004) Reconstitution of Ca2+regulated membrane fusion by synaptotagmin and SNAREs. Science 304: 435-438. CrossRef Medline

Wall MJ, Robert A, Howe JR, Usowicz MM (2002) The speeding of EPSC kinetics during maturation of a central synapse. Eur J Neurosci 15:785797. CrossRef Medline

Wang CT, Grishanin R, Earles CA, Chang PY, Martin TF, Chapman ER, Jackson MB (2001) Synaptotagmin modulation of fusion pore kinetics in regulated exocytosis of dense-core vesicles. Science 294:1111-1115. CrossRef Medline

Xu J, Pang ZP, Shin OH, Südhof TC (2009) Synaptotagmin-1 functions as a $\mathrm{Ca} 2+$ sensor for spontaneous release. Nat Neurosci 12:759-766. CrossRef Medline

Xue M, Craig TK, Shin OH, Li L, Brautigam CA, Tomchick DR, Sudhof TC, Rosenmund C, Rizo J (2010) Structural and mutational analysis of functional differentiation between synaptotagmins-1 and -7. PloS One 5:e12544. CrossRef

Xu-Friedman MA, Regehr WG (2000) Probing fundamental aspects of synaptic transmission with strontium. J Neurosci 20:4414-4422. Medline

Yao J, Gaffaney JD, Kwon SE, Chapman ER (2011) Doc2 is a Ca2+ sensor required for asynchronous neurotransmitter release. Cell 147:666-677. CrossRef Medline

Young SM Jr, Neher E (2009) Synaptotagmin has an essential function in synaptic vesicle positioning for synchronous release in addition to its role as a calcium sensor. Neuron 63:482-496. CrossRef Medline

Zhang X, Kim-Miller MJ, Fukuda M, Kowalchyk JA, Martin TF (2002) $\mathrm{Ca} 2+$-dependent synaptotagmin binding to SNAP-25 is essential for Ca2 +-triggered exocytosis. Neuron 34:599-611. CrossRef Medline

Zhang Z, Hui E, Chapman ER, Jackson MB (2010) Regulation of exocytosis and fusion pores by synaptotagmin-effector interactions. Mol Biol Cell 21:2821-2831. CrossRef Medline 